\title{
Investigation of possible solubility and dissolution advantages of cocrystals, I: Aqueous solubility and dissolution rates of ketoconazole and its cocrystals as functions of $\mathrm{pH}$
}

\author{
Jaydip M. Vasoya, ${ }^{1}$ Ankita V. Shah, ${ }^{1,2}$ Abu T.M. Serajuddin ${ }^{1, *}$ \\ ${ }^{1}$ Department of Pharmaceutical Sciences, College of Pharmacy and Health Sciences, St. John's University, 8000 Utopia \\ Parkway, Queens, NY 11439, USA (Jaydip M. Vasoya: jaydip.vasoya15@stjohns.edu) \\ ${ }^{2}$ Current address: Freund-Vector Corporation, $67544^{\text {th }}$ street, Marion, IA 52302, USA (Ankita V Shah: \\ Ankita.Shah@freund-vector.com)
}

${ }^{*}$ Corresponding author: Dr. Abu T.M. Serajuddin, email: serajuda@stjohns.edu, Office Phone: 718-990-7822

Received: February 04, 2019; Revised: April 01, 2019; Published: April 05, 2019

\begin{abstract}
Since there are conflicting reports in the literature on solubility and dissolution advantages of cocrystals over free forms, we systematically studied solubility and intrinsic dissolution rates of a weakly basic drug, ketoconazole, and its cocrystals with fumaric acid and succinic acid as functions of $\mathrm{pH}$ to determine what advantages cocrystals provide. $\mathrm{pH}$-solubility profiles were determined in two different ways: one by lowering $\mathrm{pH}$ of ketoconazole aqueous suspensions using $\mathrm{HCl}$, fumaric acid and succinic acid, and the other by adjusting $\mathrm{pH}$ of cocrystal suspensions using respective coformer acids or $\mathrm{NaOH}$. Similar $\mathrm{pH}$-solubility profiles were obtained whether free base or cocrystals were used as starting materials to determine solubility. With the addition of fumaric and succinic acids to aqueous suspensions of free base to lower $\mathrm{pH}$, the maximum solubility $\left(\mathrm{pH}_{\max }\right)$ was reached at $\mathrm{pH} \sim 3.5-4.0$, below which the solubility decreased and cocrystals formed. The solubility, however, continued increasing when $\mathrm{HCl}$ was added to ketoconazole suspension as no cocrystal or salt was formed. During determination of cocrystal solubility, a conversion to free base was observed when $\mathrm{pH}$ was raised above $\mathrm{pH}_{\max }$. Thus, $\mathrm{pH}$-solubility profiles of cocrystals resembled solubility profiles commonly encountered with salts. Above $\mathrm{pH}_{\text {max }}$ both free base and cocrystal had similar solubility under identical $\mathrm{pH}$ conditions; the solubility of cocrystal was higher only if the $\mathrm{pH}$ differed. In contrast, intrinsic dissolution rates of cocrystals at $\mathrm{pH}>\mathrm{pH} \mathrm{H}_{\max }$ under identical bulk $\mathrm{pH}$ were much higher than that of free ketoconazole since cocrystals had lower microenvironmental $\mathrm{pH}$ at the dissolving surface, where the solubility was high. Thus, cocrystals of basic drugs can potentially provide higher dissolution rates under intestinal $\mathrm{pH}$ conditions.
\end{abstract}

\section{Keywords}

Ketoconazole; cocrystal; solubility; pH effect; intrinsic dissolution rate; solid phase; phase conversion

\section{Introduction}

Crystalline forms of acidic and basic drugs or their salts have traditionally been used as active pharmaceutical ingredients (API) [1]. During the past two decades, cocrystal, which is another class of crystalline drug substance, has gained much interest in the pharmaceutical field for potential development as API [2-5]. The US Food and Drug Administration (FDA) defined cocrystals as "crystalline materials composed of two or more different molecules, typically active pharmaceutical ingredient (API) and co- 
crystal formers ('coformers'), in the same crystal lattice" [6]. To exclude solvate, hydrate, salt, etc., from such a definition, an international panel of experts defined cocrystals as "solids that are crystalline singlephase materials composed of two or more different molecular and ionic compounds generally in a stoichiometric ratio, which are neither solvates nor simple salts" [7]. The cocrystals differ from salts as no acid-base proton transfers are involved in cocrystal formation. They are usually formed by hydrogen bonding or other electrostatic interactions like $\pi-\pi$ interaction, halogen bonding, etc., between two species, and, thus, cocrystals may form even between neutral molecules [8]. It is believed that cocrystals dissociate into individual molecular species when they dissolve in aqueous media.

According to Kale et al. [9], the development of cocrystals into viable drug products could be challenging because of such factors as 'lower than expected supersaturation solubility, safety of coformer, difficulties in the manufacturing of high-dose drugs, polymorphism, atypical behavior of cocrystal in the formulation, difficulty in IVIVC, and so forth. Despite such challenges, there is active research on the development of cocrystals as potential drug products, and to the best of our knowledge, three of them have already received regulatory approvals. The first is ipragliflozin L-proline, a 1:1 cocrystal of the selective SGLT2 inhibitor ipragliflozin with L-proline, which received approval in Japan in 2014 for the treatment of Type 2 diabetes (Suglat ${ }^{\circledR}$ Tablet; Astellas) $[10,11]$; to the best of our knowledge, it is not yet available in the USA or European countries. The second is sacubitril/valsartan, which is a 1:1 cocrystal between sacubitril sodium, a neprilysin (NEP) inhibitor, and valsartan sodium, an angiotensin receptor 1 (AT1) blocker (Entresto ${ }^{\circledR}$ Tablet; Novartis); it was approved by the FDA and the European Medicines Agency (EMA) in 2015 for the treatment of long-term heart failure in adult population. The third is etrugliflozin L-PGA, which is a 1:1 cocrystal between etrugliflozin, another SGLT2 inhibitor, and L-pyroglutamic acid; it received FDA and EMA approvals in, respectively, 2017 and 2018 for the treatment of Type II diabetes (Steglatro ${ }^{\circledR}$ Tablets; Merck/Pfizer). There is not much information in the published literature on physicochemical properties of these cocrystals and what advantages they provide over those of their parent molecules.

There is the potential that a cocrystal may have higher solubility than that of the parent chemical entity. However, the solubility improvement was possibly not the primary reasons why the three marketed cocrystals were developed. In case of ipragliflozin L-proline (Suglat ${ }^{\circledR}$ ), the chemical structure of ipragliflozin indicates that, by itself, it could be water-soluble since it is a glycoside with a $-\mathrm{F}$ and several -OH groups [10], and, therefore, the cocrystal was possibly developed for certain other advantages than the solubility improvement. In case of sacubitril/valsartan (Entresto ${ }^{\circledR}$ ), both components were active moieties, and it was not a typical cocrystal between drug and therapeutically inactive coformer. Also, since both components of the cocrystal were water-soluble sodium salts, the primary advantage of cocrystal formation in this case appears to be the improvement of physicochemical properties of materials by crystallizing two otherwise amorphous or less crystalline API together as one highly crystalline drug substance [12]. Etrugliflozin is a Biopharmaceutics Classification I (BCS I) drug having good solubility and good permeability throughout the gastrointestinal $\mathrm{pH}$ range [13] and, therefore, its conversion to etrugliflozin L-PGA cocrystal (Steglatro ${ }^{\circledR}$ ) could also be for reasons other than the solubility enhancement.

Although, as mentioned above, there may be different reasons behind the development of cocrystals, much of the recent interest in this area appears to be the potential advantage of using cocrystals to improve solubility and dissolution rate of poorly water-soluble drugs $[14,15]$. However, there are mixed reports in the literature on the actual increase in aqueous solubility that may be attained by cocrystal formation. Kozak et al. [16] reported that the solubility of a neutral compound ethenzamide in water increased from around $0.80-0.85 \mu \mathrm{g} / \mathrm{mL}$ to around $1.20-1.30 \mu \mathrm{g} / \mathrm{mL}$ by cocrystallization with glutaric acid, malonic acid and maleic acid. Although this could be 1.4-1.6 time increase in solubility, considering the 
extremely low aqueous solubility of ethenzamide and the cocrystals, the increase may not be of biopharmaceutical significance. Indeed, the cocrystallization did not increase dissolution rates of ethenzamide, and, rather, cocrystals exhibited lower dissolution rates in water than the parent compound. Although possibly not suitable for neutral compounds, it could be possible that the cocrystal formation may be especially advantageous to basic and acidic compounds in cases where they do not normally form salts. Stanton and Bak [17] determined comparative solubility of ten cocrystals of an experimental basic drug, AMG $517\left(\mathrm{p} K_{\mathrm{a}}\right.$ 0.68), with ten acids ( $\mathrm{p} K_{\mathrm{a}} 3.07$ to 4.20$)$ in simulated fasted intestinal fluid (FaSIF; $5 \mathrm{mM}$ sodium taurocholate and $1.5 \mathrm{mM}$ lecithin in $\mathrm{pH} 6.8$ phosphate buffer) and observed that, as compared to the free base solubility of $5 \mu \mathrm{g} / \mathrm{mL}$, the solubility of the cocrystals ranged from 1 to $21 \mu \mathrm{g} / \mathrm{mL}$. Thus, the solubility of the compound either decreased or only marginally increased. In another study [18], the solubility of a basic drug, lamotrigine, in water was $0.154 \mathrm{mg} / \mathrm{mL}$, while the solubility of its cocrystals with glutaric acid, sorbic acid, propionic acid and acetic acid increased to 1.10, 1.12, 2.17 and $2.55 \mathrm{mg} / \mathrm{mL}$, respectively, and, thus, there were 7 to 17 times increase in aqueous solubility. However, at the same time, $\mathrm{pH}$ of the aqueous slurries during the determination of solubility decreased from 6.8 for the free base to, respectively, 5.2, 5.1, 5.0 and 4.9 for the four cocrystals. Since lamotrigine has a $\mathrm{p} K_{\mathrm{a}}$ value of 5.7 , the increase in its aqueous solubility by the formation of cocrystals may be attributed partly or fully to the $\mathrm{pH}$ change and the resultant protonation of the compound rather than cocrystal formation. Similarly, Gao et al. [19] observed a four-fold increase in solubility of adefovir dipivoxil, a basic drug, in water from 0.79 $\mathrm{mmol} / \mathrm{L}$ to $3.33 \mathrm{mmol} / \mathrm{L}$ due to cocrystal formation with saccharin that may also be attributed to the decrease in $\mathrm{pH}$ of saturated solutions from 6.7 to 3.1. Cheney et al. [20] found that when there was no difference in $\mathrm{pH}$ of saturated solutions, there was also no significant difference among solubilities of free base and cocrystals forms of drug. In this case, solubilities of lamotrigine-methyl paraben, lamotriginenicotinamide and lamotrigine-nicotinamide (monohydrate) cocrystals at 1:1 ratios and that of the lamotrigine free base in water, all having $\mathrm{pH}$ of $\sim 5.5$, were, respectively, $0.21,0.30,0.23$ and $0.28 \mathrm{mg} / \mathrm{mL}$, indicating no significant difference in solubility due to cocrystal formation. In another study, Ràfols et al. [21] compared dissolution rates of a zwitterionic compound, ciprofloxacin, and its cocrystal with resorcinol under different $\mathrm{pH}$ conditions and observed that the parent compound dissolved faster at $\mathrm{pH} 2$, while the cocrystal had somewhat higher dissolution rates in the intermediate $\mathrm{pH}$ conditions of 4, 5 and 5.5 . However, at the intestinal pH condition of 6.5, both ciprofloxacin and the cocrystal had much lower and essentially similar solubility and dissolution rates irrespective of whether the studies were conducted in buffer or fasted state simulated intestinal fluid (FaSSIF), indicating that there were no solubility and dissolution advantages of cocrystal formation under intestinal $\mathrm{pH}$ conditions.

The above review of published studies does not show any major difference in equilibrium solubility between cocrystal and neutral chemical entity or between cocrystal and free base in aqueous media, and where a difference was observed, it could possibly be explained by the change in $\mathrm{pH}$ of solutions. There are, however, several reports where differences between kinetic solubility of cocrystals and free forms of drug were observed when dissolution rates of powders were studied. It was observed that there were initial increases in drug concentrations, which decreased with time as the free base forms precipitated out $[17,22,23]$. This is analogous to the supersaturation of amorphous drugs prior to their conversion to crystalline forms [24]; when the solubility reaches equilibrium, any difference between solubility of cocrystal and free drug form diminishes or disappears.

In contrast to the above-mentioned experimental findings, several investigators have demonstrated through a combination of experimental studies and theoretical calculations that cocrystals can indeed have major solubility advantages over their respective free forms, sometimes by several orders in magnitude 
$[22,23,25,26]$. The higher solubility of cocrystals as the function of $\mathrm{pH}$ in these studies were obtained by applying a new 3-step process: first, drug and coformer concentrations in equilibria with cocrystals were measured at $\mathrm{pH}$ values of interest; second, cocrystal solubility and solubility product $\left(K_{\mathrm{sp}}\right)$ were determined from the measured equilibrium concentrations; and, third, the $\mathrm{pH}$ dependence of cocrystal solubility is theoretically calculated from $K_{\mathrm{sp}}$ of cocrystal, $\mathrm{p} K_{\mathrm{a}}$ values of drug and coformer, and corresponding solubility equations [22]. Based on such theoretical calculations, Chen et al. [22] observed much higher solubility for 1:1 cocrystals of ketoconazole, a basic drug $\left(p K_{\mathrm{a}} 2.94\right.$ and 6.51) [27], with fumaric acid, succinic acid and adipic acid in the $\mathrm{pH}$ range of 4 to 7 as compared to that of the free base in the same $\mathrm{pH}$ range. Martin et al. [28] also observed 75 to 100 times higher solubility of ketoconazole cocrystals with fumaric acid, succinic acid and adipic acid in water than that of ketoconazole free base. However, in the latter case, the $\mathrm{pH}$ values of the slurries of cocrystals in water decreased from the initial 5.8 to the range of 3.4 to 4.1 , where the solubility of the drug could be much higher and thus be responsible for the observed difference between cocrystal and drug solubility.

The inconsistencies between above-mentioned experimental and theoretical findings indicate that much additional work is necessary to elucidate what advantages cocrystals may have over their free forms with respect to solubility and dissolution rate. Therefore, the present investigation has been undertaken to systematically determine solubility and dissolution rates of a basic drug, ketoconazole, and two of its cocrystals with fumaric acid and succinic acid as functions of $\mathrm{pH}$. Although not many studies on $\mathrm{pH}$ versus solubility of cocrystals have been reported in the literature, there are numerous reports on the effect of $\mathrm{pH}$ on solubility of acids, bases and their salt forms available [29-32]. There are also numerous reports on higher dissolution rates of salts as compared to their respective free base or acid forms due to change in $\mathrm{pH}$ and increased drug solubility in diffusion layers of solids during dissolution testing [29,32,33]. It was, therefore, of interest to determine whether cocrystals could influence drug solubility and dissolution rate analogous to salts and, if any differences in performance of salts and cocrystals existed, what were those differences. Based on these considerations, primary objectives of the present study with ketoconazole and its cocrystals were the following: (a) determine equilibrium solubility of free base and cocrystals as functions of $\mathrm{pH}$ to ascertain what differences exist between the solubility of two forms, (b) determine solid phases in equilibria with solutions to study whether any conversion from cocrystal to free base or vice versa occur during solubility vs. $\mathrm{pH}$ determination, (c) determine possible similarity and dissimilarity between $\mathrm{pH}$ vs. solubility of cocrystal with $\mathrm{pH}$-solubility profiles of salts reported in the literature and, in particular, whether any $\mathrm{pH}_{\max }$ ( $\mathrm{pH}$ of maximum solubility) exists during the interconversion of cocrystal and free base like that with salts, and (d) determine comparative intrinsic dissolution rates of cocrystals and the free base at different $\mathrm{pH}$ conditions to ascertain what role cocrystal formation plays in dissolution and whether there are any impacts of microenvironmental $\mathrm{pH}$ at the dissolving solid surface on the dissolution rate.

\section{Experimental}

\section{Materials}

Ketoconazole was purchased from Alfa Aesar, a Thermo Fisher Scientific company (Ward Hill, MA, USA) and used as received. Succinic acid and fumaric acid were purchased, respectively, from VWR Life Sciences (Radnor, PA, USA) and Fluka Analytical (Fisher Scientific, Pittsburg, USA). All other solvents and reagents used in this investigation were of analytical grade or better. Distilled water was used, as necessary, for all experiments. 


\section{Preparation of ketoconazole cocrystals}

Cocrystals were prepared by modifying solvent evaporation methods reported earlier [28]. In a typical experiment for the preparation of ketoconazole-succinic acid cocrystal, 2 millimoles of ketoconazole (1063 $\mathrm{mg}$ ) and 2.2 millimoles of succinic acid $(260 \mathrm{mg}$ ) were dissolved in $4 \mathrm{~mL}$ of 3:1 v/v chloroform-methanol solvent mixture by stirring on a hot plate magnetic stirrer at $60-65{ }^{\circ} \mathrm{C}$. The solution was then kept under vacuum for solvent evaporation and thereby cocrystal precipitation. After complete evaporation of solvent, the dried material was washed with $5 \mathrm{~mL}$ of methanol to remove any unconverted free drug and coformer. The washed cocrystals were dried in a vacuum oven at $50{ }^{\circ} \mathrm{C}$ to remove any residual methanol. Dried cocrystals were analyzed using differential scanning calorimetry (DSC), powder X-ray diffraction (PXRD) and Raman spectroscopy. The purity of cocrystals or the presence of any unconverted ketoconazole or succinic acid with cocrystals were assessed by DSC, PXRD and Raman spectroscopy patterns. A similar method was also used for the preparation of ketoconazole-fumaric acid cocrystal where 2 millimoles of ketoconazole (1063 mg) and 2.2 millimoles of fumaric acid $(255.4 \mathrm{mg}$ ) were dissolved in $5 \mathrm{~mL}$ of $3: 2 \mathrm{v} / \mathrm{v}$ chloroformmethanol mixture. Multiple batches of the two cocrystals were prepared for use in the course of the present investigation and the quality of materials was found to be consistently similar.

\section{Differential scanning calorimetry (DSC)}

The DSC scans were recorded using the Q200 differential scanning calorimeter (TA instruments, Wilmington, DE, USA). Accurately weighed samples (4-6 mg each) were taken into Tzero aluminum pans and sealed with hermetic lids with pin holes. Samples were heated at the rate of $10{ }^{\circ} \mathrm{C} / \mathrm{min}$ from $5{ }^{\circ} \mathrm{C}$ to 350 ${ }^{\circ} \mathrm{C}$ under nitrogen flush at the rate of $50 \mathrm{~mL} / \mathrm{min}$. Data acquisition was performed using TA analysis software.

\section{Powder X-ray diffraction (PXRD)}

Powder X-ray diffraction analysis was conducted using Shimadzu XRD-6000 diffractometer (Shimadzu, Kyoto, Japan), equipped with $\mathrm{Ni}$ filter and monochromatic $\mathrm{Cu}$-Ka radiation source. The diffractometer was operated with a copper anode tube at the generator voltage and the current of $40 \mathrm{kV}$ and $30 \mathrm{~mA}$, respectively. X-ray patterns of all solid samples were recorded between $5^{\circ}$ to $50^{\circ}$ two-theta angles at the rate of $2^{\circ}$ per minute. All PXRD patterns were analyzed for characteristic peaks of ketoconazole and its cocrystals.

\section{Raman spectroscopy}

Solid samples as well as the excess solids present in suspensions during the determination of aqueous solubility were analyzed by Raman spectroscopy. Raman spectra were generated with the RXN1 system (Kaiser Optics, Ann Arbor, MI, USA) using fiber optic probe emitting $785 \mathrm{~nm}$ laser with the total power of $400 \mathrm{mw}$. Data acquisition was performed using IC Raman 4.1 software from Mettler Toledo (Columbus, $\mathrm{OH}$, USA). For in situ analysis of solids suspended in aqueous media, aliquots of suspensions were transferred into small aluminum cups and then exposed to laser beam through non-contact Raman PhAT Probe (Kaiser Optics) in dark. After acquisition of the spectrum, the sample was poured back into the vial and the shaking was continued.

\section{HPLC analysis}

Drug concentration was analyzed by reverse phase high pressure liquid chromatography (HPLC) (HP 1100 series, Agilent Technologies, Wilmington, DE). The mobile phase consisted of 3:1 ratio of acetonitrile: acetate buffer, where, for the preparation of acetate buffer, $0.04 \mathrm{M}$ sodium acetate trihydrate solution was prepared in distilled water, $\mathrm{pH}$ was adjusted to 4.5 using glacial acetic acid, and to $1000 \mathrm{~mL}$ of this solution, 
$2 \mathrm{~mL}$ of triethyl amine was added. For HPLC analysis, C18 column (Agilent ZORBAX Eclipse XDB columns, Agilent Technologies, Santa Clara, CA) was used with $0.75 \mathrm{~mL} / \mathrm{min}$ flow rate, $230 \mathrm{~nm}$ wavelength, and $25^{\circ} \mathrm{C}$ temperature.

\section{Determination of $\mathrm{pH}$ vs solubility profiles}

In a 'white paper' published by an international panel of experts, Avdeef et al. [34] reported that a systematic determination of solubility by taking into consideration such factors as equilibration time, stirring rate, equilibrium $\mathrm{pH}$, temperature, compositions of aqueous media (buffers, ionic strength, etc.), characteristics of solid phase, and so forth, is critically important for accurate measurement of solubility of drug substances and especially when the drug substances are ionizable. The composition of solid phases in equilibria with aqueous media may also change depending on the buffering agents used [35]. For these reasons, we have undertaken systematic determination of aqueous solubility of ketoconazole, an ionizable drug, under different experimental conditions, as described below, by taking into considerations the recommendations made in these publications.

\section{Ketoconazole solubility by $\mathrm{pH}$ adjustment with $\mathrm{HCl}$}

The $\mathrm{pH}$-solubility profile of ketoconazole was generated by adjusting $\mathrm{pH}$ of its suspension in water using different concentrations of $\mathrm{HCl}$ solutions $(0.001$ to $1 \mathrm{M})$, as necessary, to obtain the desired $\mathrm{pH}$. In a typical experiment, $5 \mathrm{~mL}$ of distilled water was taken in a $20-\mathrm{mL}$ glass vial with a small amount of ketoconazole (5-10 mg), and the vial was shaken in a water bath shaker (Innova 3100, New Brunswick Scientific Co., Edison, NJ) at $25^{\circ} \mathrm{C}$. Multiple vials were prepared using different concentration of $\mathrm{HCl}$ solutions $(0.001 \mathrm{M}$ to $1 \mathrm{M}$ ) so that different $\mathrm{pH}$ values could be attained, and, when needed, more amount of free base was added to maintain excess solid in the vials. Ketoconazole solubility was measured at enough number of $\mathrm{pH}$ points by repeating above mentioned procedure as exact replicates of $\mathrm{pH}$ point is experimentally difficult. The $\mathrm{pH}$ of the suspension was measured at 4 and $24 \mathrm{~h}$ and concentrations of ketoconazole at these time points were determined by filtering 0.5 to $1 \mathrm{~mL}$ of aliquots through poly(vinylidene fluoride) (PVDF) filter with 0.45 micron pore size and analyzing filtrate by $\mathrm{HPLC}$. Additional $\mathrm{HCl}$ solution and excess ketoconazole were added to the suspension in vial and shaken for another $\mathrm{pH}$ point, and the process was repeated until enough points on the $\mathrm{pH}$ scale were obtained. More than one suspension in different vials were used to generate a complete profile.

\section{Cocrystal solubility by adjusting $\mathrm{pH}$ with coformer acids and $\mathrm{NaOH}$}

Cocrystal solubility at different $\mathrm{pH}$ values was determined using solutions of coformer acid (succinic acid or fumaric acid) to lower $\mathrm{pH}$ of aqueous suspensions and by adding $\mathrm{NaOH}$ solutions to adjust higher $\mathrm{pH}$. Excess amount of cocrystal was dispersed in $5 \mathrm{~mL}$ of distilled water in a $20 \mathrm{~mL}$ glass vial, and when the cocrystal suspension reached a specific $\mathrm{pH}$ after equilibration in a water bath at $25^{\circ} \mathrm{C}$ by shaking, coformer solutions

(4 mg/mL fumaric acid or $50 \mathrm{mg} / \mathrm{mL}$ succinic acid) were added to respective cocrystal suspensions to lower $\mathrm{pH}$, and the vials were shaken for additional $96 \mathrm{~h}$ at $25{ }^{\circ} \mathrm{C}$ in water bath. After equilibration, the concentration of ketoconazole at the attained $\mathrm{pH}$ was determined by withdrawing $0.5-1 \mathrm{~mL}$ of aliquot for filtration through 0.45 micron filter, followed by HPLC analysis. For higher pH, different volumes of $0.1 \mathrm{M}$ $\mathrm{NaOH}$ solution was added to cocrystal suspensions and shaken for $96 \mathrm{~h}$, and the drug concentration was determined according to the method described above. The solid phase in equilibrium with a suspension was analyzed in situ intermittently by Raman spectroscopy and by DSC at the end of the experiment for any conversion of cocrystal to free base. 


\section{Cocrystal solubility in buffered/non-buffered media}

Cocrystal solubilities were determined at pH 1 solution $(0.1 \mathrm{M} \mathrm{HCl}), \mathrm{pH} 2 \mathrm{HCl}$ buffer), $\mathrm{pH} 5$ acetate buffer and $\mathrm{pH} 8$ phosphate buffer. Buffers were prepared according to the United States Pharmacopeia (USP) procedures. For the determination of solubility, $5 \mathrm{~mL}$ of each buffer was equilibrated with excess cocrystal in a $20 \mathrm{~mL}$ glass vial and shaken for $96 \mathrm{~h}$ in a water bath shaker at $25{ }^{\circ} \mathrm{C}, 0.5-1 \mathrm{~mL}$ of samples were withdrawn at 24 and $96 \mathrm{~h}$, and $\mathrm{pH}$ of the solution and concentration of ketoconazole were measured. Aliquots were filtered by 0.45 -micron PVDF filter and analyzed by HPLC. The solid phase was analyzed by Raman spectroscopy.

\section{Ketoconazole solubility by adjusting $\mathrm{pH}$ with fumaric acid and succinic acid}

$\mathrm{pH}$-solubility profiles of ketoconazole were also generated using the two coformer acids, e.g., succinic acid and fumaric acid. A series of solutions with different concentrations of acids were prepared and $3 \mathrm{~mL}$ quantities of these solutions were distributed in separate glass vials. For the determination of ketoconazole solubility versus $\mathrm{pH}$ using succinic acid, the concentration of acid ranged from $100 \mu \mathrm{g} / \mathrm{mL}$ to $50 \mathrm{mg} / \mathrm{mL}$, while, in case of fumaric acid, the concentration of acid ranged $50 \mu \mathrm{g} / \mathrm{mL}$ to $2 \mathrm{mg} / \mathrm{mL}$; the difference in acid concentration was due to difference in aqueous solubility of acids, fumaric acid being much less soluble. To each of these solutions, excess amounts of ketoconazole ( $10-15 \mathrm{mg}$ more than the expected solubility at a specific $\mathrm{pH}$ ) was added and kept for shaking in a water bath shaker at $25{ }^{\circ} \mathrm{C}$ for up to $96 \mathrm{~h}$. Aliquots of suspensions (0.5-0.7 mL each) were, however, withdrawn from each vial after 4, 24 and $96 \mathrm{~h}$ of shaking for analysis of drug concentration by HPLC according to the method described earlier. For the analysis of solid phase, contents of the vials were transferred to 3-mL Eppendorf tubes and centrifuged using Beckman GS $6 \mathrm{R}$ centrifuge at $2000 \mathrm{RPM}$ for $5 \mathrm{~min}$. After centrifugation, the supernatants were removed and solid contents were dried in a vacuum oven at $50{ }^{\circ} \mathrm{C}$, which were then analyzed by DSC and Raman spectroscopy.

\section{Solubility of 1:1 physical mixtures of ketoconazole with different coformers}

Aqueous solubility was also determined for 1:1 molar physical mixtures of ketoconazole with each of the coformers (succinic acid and fumaric acid). In this study, different quantities of the mixtures (12 $\mathrm{mg}$ to 350 $\mathrm{mg}$ ) were added to different $20 \mathrm{~mL}$ glass vials, and then $5 \mathrm{~mL}$ of water was added to each vial. Thus, the volume of water in each vial remained the same and only the amount of material added differed. The vials were shaken in the water bath shaker at $25^{\circ} \mathrm{C}$ and $250 \mathrm{RPM}$ to achieve equilibrium solubility. $\mathrm{pH}$ of the suspensions differed because there were different amounts of acids added in the same volume of water, and all the acids dissolved in water. Samples were withdrawn from each vial at 4, 24 and $96 \mathrm{~h}$ to measure drug concentration, as described earlier. The solid phase of the vials was analyzed using Raman spectroscopy to determine the identity of equilibrium species. From some of the vials, solid contents were separated by centrifugation, dried in a vacuum oven, and then analyzed by DSC.

\section{Intrinsic dissolution rate}

Intrinsic dissolution profiles of ketoconazole free base and its cocrystals were determined using an intrinsic dissolution apparatus (Agilent Technologies, Santa Clara, CA) with $0.5 \mathrm{~cm}^{2}$ exposed surface area at $25{ }^{\circ} \mathrm{C}$. For each determination, $100 \mathrm{mg}$ of powder was compressed into pellet by Carver press at 1 ton pressure for 10 seconds. The apparatus with the exposed surface of the material was immersed into 250 $\mathrm{mL}$ of dissolution medium and rotated at $200 \mathrm{RPM}$. $\mathrm{pH}$ of dissolution media during the intrinsic dissolution testing were maintained by two different methods: in one case, unbuffered media were used where either $0.1 \mathrm{M} \mathrm{HCl}$ or $0.1 \mathrm{M} \mathrm{NaOH}$ were added to keep pH constant at 3, 4 or $5( \pm 0.15)$, and in the second case, $\mathrm{pH} 3$, 4 and 5 phthalate buffers prepared according to the USP were used as dissolution media to keep $\mathrm{pH}$ 
constant. Two $\mathrm{mL}$ of aliquot was withdrawn at each of 5, 15, 30, 60, 90 and 120 min time points, filtered by 0.45-micron PVDF filter, and analyzed by HPLC for drug concentration.

\section{Results and Discussion}

\section{Ketoconazole cocrystals}

Ketoconazole-fumaric acid and ketoconazole-succinic acid cocrystals prepared by the solvent evaporation method in the present investigation were analyzed by differential scanning calorimetry (DSC) and powder X-ray diffraction (PXRD) to assess their crystallinity and purity. DSC scans of two cocrystals as well as those of parent compounds (ketoconazole, fumaric acid and succinic acid) are shown in Fig. 1, and the corresponding PXRD patterns are given in Fig. 2. Ketoconazole showed a melting endotherm at $150{ }^{\circ} \mathrm{C}$, while ketoconazole-fumaric acid and ketoconazole-succinic acid cocrystals showed melting endotherms at $170{ }^{\circ} \mathrm{C}$ and $167{ }^{\circ} \mathrm{C}$, respectively; these values are in agreement with those reported elsewhere in the literature [28]. The relatively sharp endotherms indicated that the cocrystals were highly crystalline, and the absence of any separate peaks for ketoconazole alone or free acids in DSC scans confirmed the absence of any impurity due to the presence of unconverted ketoconazole or coformers in cocrystals. The PXRD patterns in Fig. 2 showed characteristic peaks for ketoconazole cocrystals and their parent materials, indicating that the cocrystals are highly crystalline. Raman spectra in Fig. 3 also demonstrated that all the materials have distinct spectral patterns that are different from each other.

Ketoconazole is a weakly basic drug having two $\mathrm{p} K_{\mathrm{a}}$ values of 2.94 and 6.51 [27]. It formed cocrystals with weak organic acids such as succinic acid and fumaric acid. Succinic acid has $p K_{\mathrm{a}}$ values of 3.93 and 5.30 for its first and second ionization, respectively, while fumaric acid has $p K_{\mathrm{a}}$ values of 2.74 and 4.17 for its first and second ionization, respectively. Childs et al. [36] postulated that a $\mathrm{p} K_{\mathrm{a}}$ difference of greater than 3 between a basic drug and its conjugate acid $\left(\Delta \mathrm{p} K_{\mathrm{a}}>3\right)$ favors salt formation rather than cocrystals, while the cocrystal formation is favored when $\Delta \mathrm{p} K_{\mathrm{a}}$ is $<3$. The $\Delta \mathrm{p} K_{\mathrm{a}}$ for ketoconazole and succinic acid is $<3$ and, therefore, the formation of cocrystal was expected. Although the $\mathrm{p} K_{\mathrm{a}}$ difference between ketoconazole and fumaric acid is $>3$, a cocrystal, and no salt, was formed. The cocrystal formation could be due to hydrogen bonding between acetyl group of ketoconazole and one of the acid groups in succinic acid or fumaric acid. The second carboxyl groups in the acids could also form hydrogen bonds with imidazole $\mathrm{N}$-atom of ketoconazole [28]. As reported by Martin et al. [28] for ketoconazole-fumaric acid pair, hydrogen bonding is favored instead of proton transfer due to spatial crystal environment in ketoconazole-fumaric acid cocrystals. They also observed that the structure of ketoconazole-succinic acid cocrystal completely resembles that of ketoconazole-fumaric acid cocrystal.

Raman spectra shown in Fig. 3 also indicate cocrystal formation. Ketoconazole has a characteristic peak at $1640 \mathrm{~cm}^{-1}$ for $-\mathrm{C}=\mathrm{O}$ stretch while Raman spectra of succinic acid shows a peak at $1650 \mathrm{~cm}^{-1}$ for $-\mathrm{C}=0$ (carbonyl group) of acid [37,38]. In the ketoconazole-succinic acid cocrystal spectrum, the $-\mathrm{C}=\mathrm{O}$ peak shifts to $1724 \mathrm{~cm}^{-1}$ because of hydrogen bond formation between one of the carboxylic acid groups of succinic acid and the $-\mathrm{C}=\mathrm{O}$ group of ketoconazole. This change in Raman spectrum of ketoconazole-succinic acid cocrystal shows the formation of hydrogen bond. In this cocrystal, one more hydrogen bond formation occurs between the second carboxyl group of succinic acid and nitrogen of imidazole group of ketoconazole. Due to the participation of nitrogen of imidazole (ketoconazole) in hydrogen bond formation, a shift in $\mathrm{N}=\mathrm{C}-\mathrm{H}$ stretch from $3113 \mathrm{~cm}^{-1}$ to $3131 \mathrm{~cm}^{-1}$ could be observed in the cocrystal as compared to the ketoconazole spectrum. In the ketoconazole-succinic acid cocrystal, the four-member ring formation involving two ketoconazole and two succinic acid moieties was observed [28], which is supported by two hydrogen bonds linking all four molecules in a circuit network. 


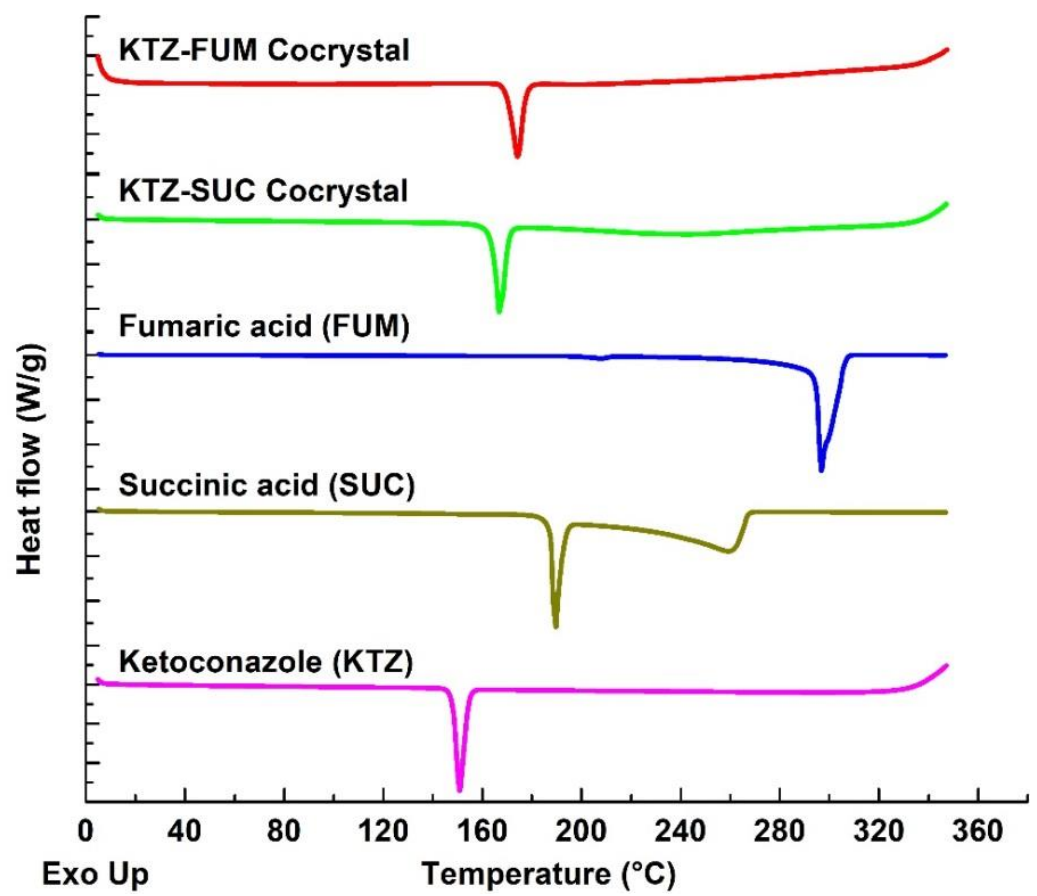

Figure 1. Comparative DSC scans of ketoconazole, succinic acid, fumaric acid, and ketoconazole cocrystals with fumaric acid and succinic acid.

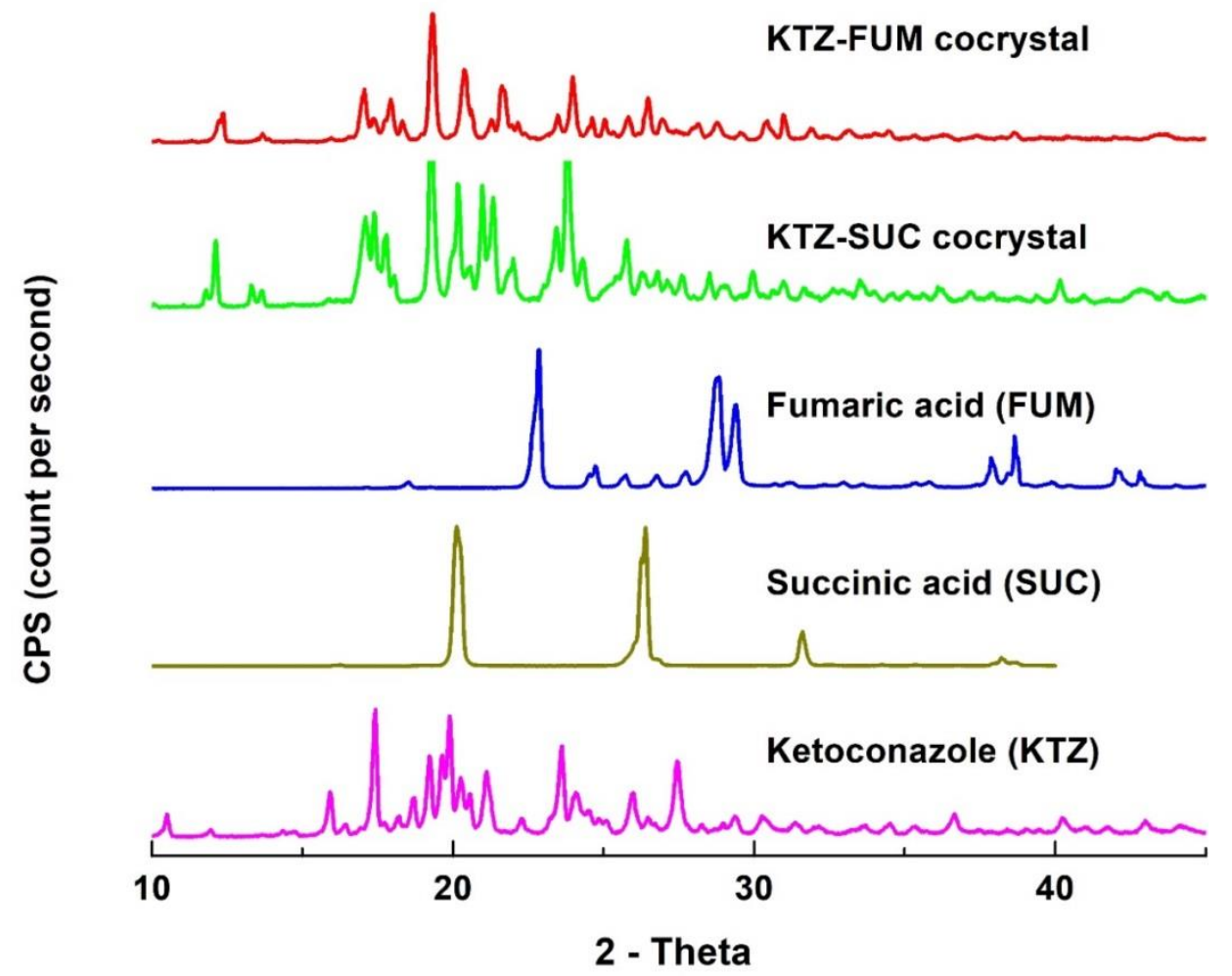

Figure 2. Comparative powder X-ray patterns of ketoconazole, succinic acid, fumaric acid, and ketoconazole cocrystals with fumaric acid and succinic acid.

Similarly, Raman spectrum of fumaric acid shows peak at $1682 \mathrm{~cm}^{-1}$ for the carboxylic acid group that shifts towards a higher wave number of $1718 \mathrm{~cm}^{-1}$ due to hydrogen bonding with $-\mathrm{C}=\mathrm{O}$ group of ketoconazole in the cocrystal. The ketoconazole $-\mathrm{C}=\mathrm{O}$ peak shifts from $1640 \mathrm{~cm}^{-1}$ to $1665 \mathrm{~cm}^{-1}$ due to hydrogen bond formation with the cocrystal. Also, a hydrogen bond is formed between the second carboxylic acid group of fumaric acid and nitrogen of imidazole group in ketoconazole. Thus, ketoconazole- 
fumaric acid cocrystal forms a similar 4-member ring structure as that of the ketoconazole-succinic acid cocrystal.

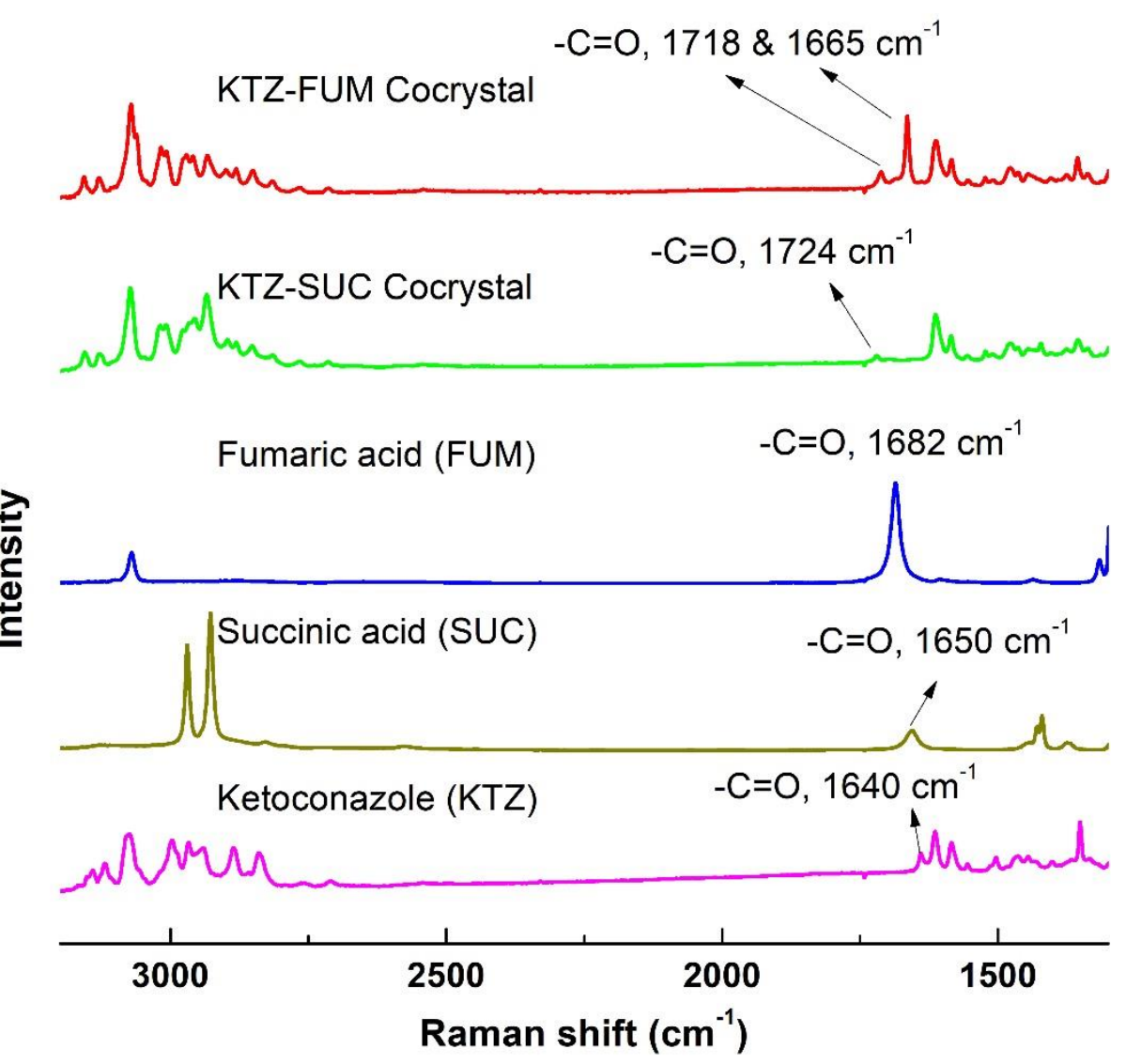

Figure 3. Comparative Raman spectral scans of ketoconazole, succinic acid, fumaric acid, and ketoconazole cocrystals with fumaric acid and succinic acid.

\section{pH versus solubility of ketoconazole base}

For a comparison of solubility of the basic drug, ketoconazole, with that of cocrystals, the pH-solubility profile of ketoconazole was determined using $\mathrm{HCl}$ to adjust $\mathrm{pH}$. The results are tabulated in Table 1, and they are also plotted in Fig. 4 for visual observation of the nature of change in solubility as a function of pH. The intrinsic solubility of the ketoconazole free base, i.e., the solubility of the nonprotonated species, at $\mathrm{pH}$ higher than 8 was found to be around $2 \mu \mathrm{g} / \mathrm{mL}$, and the solubility increased exponentially as the pH was decreased gradually in the range of approximately 5.5 and 3, as indicated by the linearity of the semilogarithmic plot in Fig. 4. The highest solubility of $148.3 \mathrm{mg} / \mathrm{mL}$ (not shown in figure) for ketoconazole at pH 3.1 was measured in the present study, when the solution turned orange. Any further reduction in $\mathrm{pH}$ to increase solubility by still keeping the solution in equilibrium with a solid phase was not possible; the added ketoconazole dissolved if the $\mathrm{pH}$ was decreased by adding concentrated $\mathrm{HCl}$ and the $\mathrm{pH}$ went back to around 3 when more solid ketoconazole was added to the solution. Although there is a report that the preparation of ketoconazole dihydrochloride salt having very high solubility and the melting point of $229^{\circ} \mathrm{C}$ is feasible [39], neither the monohydrochloride salt nor the dihydrochloride salt precipitated out during the $\mathrm{pH}$-solubility study in the present investigation. Attempts to crystallize ketoconazole hydrochloride salts from anhydrous methanolic solutions in separate studies were also negative as they yielded amorphous materials. 
Table 1 Equilibrium solubility of ketoconazole base at different $\mathrm{pH}$ at $25^{\circ} \mathrm{C}$, where $\mathrm{pH}$ of aqueous suspensions was lowered using $\mathrm{HCl}$ solutions. $\mathrm{pH}$ and corresponding solubilities from individual vials, including repeating observations, are shown.

\begin{tabular}{|c|c|c|c|cc|}
\hline $\begin{array}{c}\text { pH of } \\
\text { suspension }\end{array}$ & $\begin{array}{c}\text { Solubility } \\
(\mu \mathrm{g} / \mathrm{mL})\end{array}$ & $\begin{array}{c}\mathrm{pH} \text { of } \\
\text { suspension }\end{array}$ & $\begin{array}{c}\text { Solubility } \\
(\mu \mathrm{g} / \mathrm{mL})\end{array}$ & $\begin{array}{c}\mathrm{pH} \text { of } \\
\text { suspension }\end{array}$ & $\begin{array}{c}\text { Solubility } \\
(\mu \mathrm{g} / \mathrm{mL})\end{array}$ \\
\hline $\mathbf{3 . 1}$ & 148320 & 4.28 & 729 & 7.23 & 4 \\
\hline $\mathbf{3 . 3 5}$ & 5457 & 4.48 & 345 & 7.23 & 4 \\
\hline $\mathbf{3 . 3 5}$ & 5429 & 4.56 & 354 & 7.27 & 3 \\
\hline $\mathbf{3 . 3 7}$ & 7100 & $\mathbf{4 . 5 6}$ & 354 & $\mathbf{7 . 7 2}$ & 2 \\
\hline $\mathbf{3 . 5 8}$ & 3425 & 4.95 & 178 & 7.92 & 3 \\
\hline $\mathbf{3 . 6 7}$ & 3031 & 4.99 & 175 & $\mathbf{8 . 4 9}$ & 2 \\
\hline $\mathbf{3 . 7 1}$ & 2782 & 4.99 & 175 & & \\
\hline $\mathbf{3 . 8 1}$ & 1931 & 7.12 & 5 & & \\
\hline
\end{tabular}

As mentioned earlier, ketoconazole has two $p K_{\mathrm{a}}$ values of 2.94 and 6.51 , and the increase in solubility of the compound plotted in Fig. 4 is obviously due to the effect of the $p K_{a}$ of 6.51 , since any significant effect of the $\mathrm{p} K_{\mathrm{a}}$ of 2.94 may not be observed in the $\mathrm{pH}$ range studied. Therefore, the solubility data are plotted in the figure according to the Equation (1), where $S_{\mathrm{T}}$ is the total solubility at a particular $\mathrm{pH}$ and $[\mathrm{B}]_{\mathrm{S}}$ is the intrinsic solubility of the free base [31], which in case of ketoconazole was taken as $2 \mu \mathrm{g} / \mathrm{mL}$.

$$
S_{T, b a s e}\left(p H>p H_{\text {max }}\right)=[B]_{S}\left(1+\frac{\left[H_{3} O^{+}\right]}{K_{a}}\right)=[B]_{S}\left(1+10^{p K_{a}-p H}\right)
$$

The linearity of the semi-logarithmic plot of solubility as a function of $\mathrm{pH}$ in the $\mathrm{pH}$ range of $\sim 6.0$ to $~ 3.5$ showed that the increase in solubility follows the classic Henderson-Hasselbalch equation. There was no deviation from the linearity of the graph until the pH decreased below 3.5 since there was no effect of the second $\mathrm{p} K_{\mathrm{a}}$ value on the solubility of ketoconazole at higher $\mathrm{pH}$. The nonlinear increase in solubility around $\mathrm{pH} 3$ in the semi-logarithmic plot could be due to second protonation of the molecule because of the effect of the second $\mathrm{p} K_{\mathrm{a}}$ value.

\section{pH versus solubility of ketoconazole cocrystals}

The solubility of ketoconazole cocrystal as a function of $\mathrm{pH}$ was determined by adjusting the $\mathrm{pH}$ of a saturated solution of cocrystal to a lower $\mathrm{pH}$ by adding aqueous solutions of respective coformer and to a higher $\mathrm{pH}$ by adding $\mathrm{NaOH}$ aqueous solutions. The results are plotted in Fig. 5 . When excess amounts of fumaric acid and succinic acid cocrystals were dissolved in water, $\mathrm{pH}$ values of the saturated solutions were, respectively, 4.1 and 4.2, and the solubilities of cocrystals were, respectively, 2.6 and $1.5 \mathrm{mg} / \mathrm{mL}$ (as ketoconazole equivalents). As examined by DSC and PXRD analyses, the solid phases in equilibria with these cocrystal solutions in water were mixtures of cocrystals and free base, the fraction of free base being relatively very small in the total solid. As shown in Fig. 5, when $\mathrm{pH}$ values of cocrystal solutions in water were lowered by adding respective acidic coformers, there were initial decreases in solubility, which then increased with continued addition of coformer solutions to further decrease $\mathrm{pH}$. The solid phases in equilibria with these solutions were only cocrystals since no conversion to free base occurred when excess coformer was added. The mechanism of the decrease in solubility that was followed by the increase has 
not been elucidated. It is possible that some forms of complexes may exist between ketoconazole and coformers in solution in this $\mathrm{pH}$ range and the solubility profiles reflect the change in nature and solubility of such complexes.

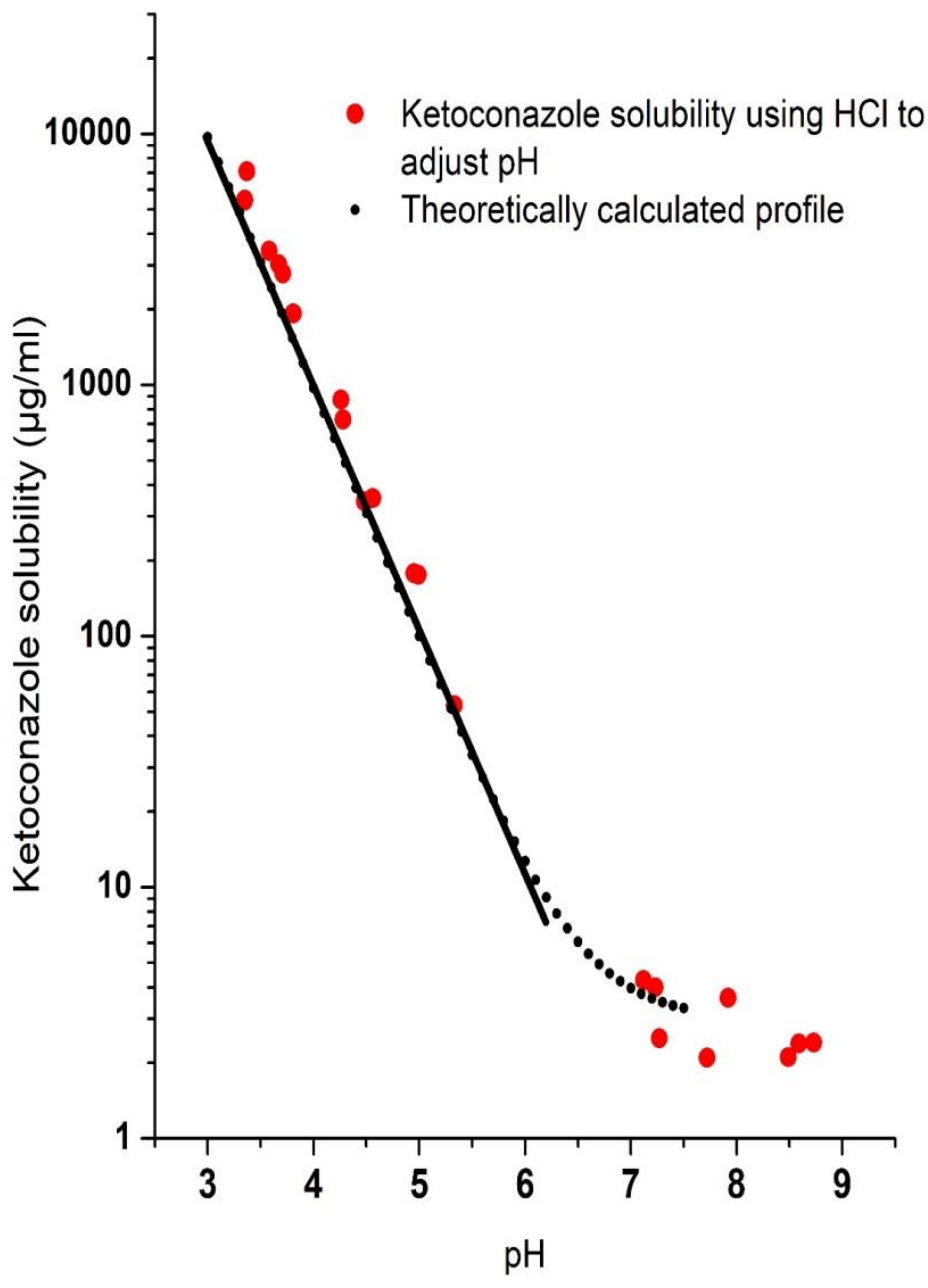

Figure 4. Ketoconazole $\mathrm{pH}$-solubility profile generated by using hydrochloric acid to adjust $\mathrm{pH}$.

When $\mathrm{pH}$ values of the saturated solutions of ketoconazole cocrystals with fumaric acid and succinic acid were increased by adding $\mathrm{NaOH}$ solutions, the solubility decreased for both cocrystals. The $\mathrm{pH}$ versus solubility of ketoconazole free base, which was generated by the adjustment of $\mathrm{pH}$ using $\mathrm{HCl}$ or $\mathrm{NaOH}$, is also plotted in Fig. 5. A comparison of the three plots show that the solubility of the free base and the two cocrystals were identical at $\mathrm{pH}>4.1$. Solid phases in equilibria with solutions during the determination of $\mathrm{pH}$-solubility profiles under these $\mathrm{pH}$ conditions were mixtures of ketoconazole free base and cocrystals, and only at $\mathrm{pH}>5$, the full conversion of the solid phase to the free base form was observed. It is apparent that when alkali is added to adjust $\mathrm{pH}$, it neutralizes the acidic coformers for partial conversion of the solid phase to the free base, and when sufficient alkali is added and the $\mathrm{pH}$ rises above 5 , all the excess cocrystals convert to the free base. It is possible that initially formed free base coated the surface of cocrystal particles and thereby only the free base was in equilibrium with the solution. These results demonstrate that the solubility of cocrystals follows the general $\mathrm{pH}$-solubility profile of free base above a certain critical $\mathrm{pH}$ value, where the solubility decreases with the increase in $\mathrm{pH}$. This is analogous to the decrease in solubility of pharmaceutical salts above the $\mathrm{pH}_{\max }$, i.e., the $\mathrm{pH}$ of maximum solubility, as a function of $\mathrm{pH}$ [32]. 


\section{Solubility of ketoconazole cocrystals at different $\mathrm{pH}$ in buffered solutions}

In the above section, Fig. 5 shows a decrease in solubility of ketoconazole cocrystals with the increase in $\mathrm{pH}$. However, as mentioned earlier, there are reports in the literature where increased solubility of cocrystals under high $\mathrm{pH}$ conditions was predicted based on theoretical calculations only [20]. Since, for the development of drug products, it is necessary to experimentally ascertain solubility and dissolution rate in the gastrointestinal $\mathrm{pH}$ range, the solubility of ketoconazole cocrystals was also studied in buffered solutions and compared with that of the free base.

As shown in Fig. 5, there are certain limits how much lowering of $\mathrm{pH}$ may be achieved by adding acidic coformer solutions. For this reason, the solubility of ketoconazole cocrystals was also determined in acidic buffers to mimic gastric $\mathrm{pH}$ conditions. The results of these studies are tabulated in Table 2. It may be noted in this table that there were certain shifts in $\mathrm{pH}$ of buffers after equilibration with solids, which may be attributed to the liberation of either fumaric acid or succinic acid from cocrystals. The solubility of free base and cocrystals somewhat differed due to the $\mathrm{pH}$ shift. Difference in buffer compositions and ionic strength may also play roles in the observed difference in solubility in Table 2 . However, overall, Table 2 shows the solubility of ketoconazole cocrystals indeed decreases at relatively higher $\mathrm{pH}$ conditions and the solubility of free base and cocrystals under such $\mathrm{pH}$ conditions are essentially similar. Such similarity in $\mathrm{pH}-$ solubility profiles of ketoconazole cocrystals and free base is analogous to the similarity in $\mathrm{pH}$-solubility profiles of salt and free base irrespective of whether one or the other is used as starting material to determine solubility $[30,33]$.

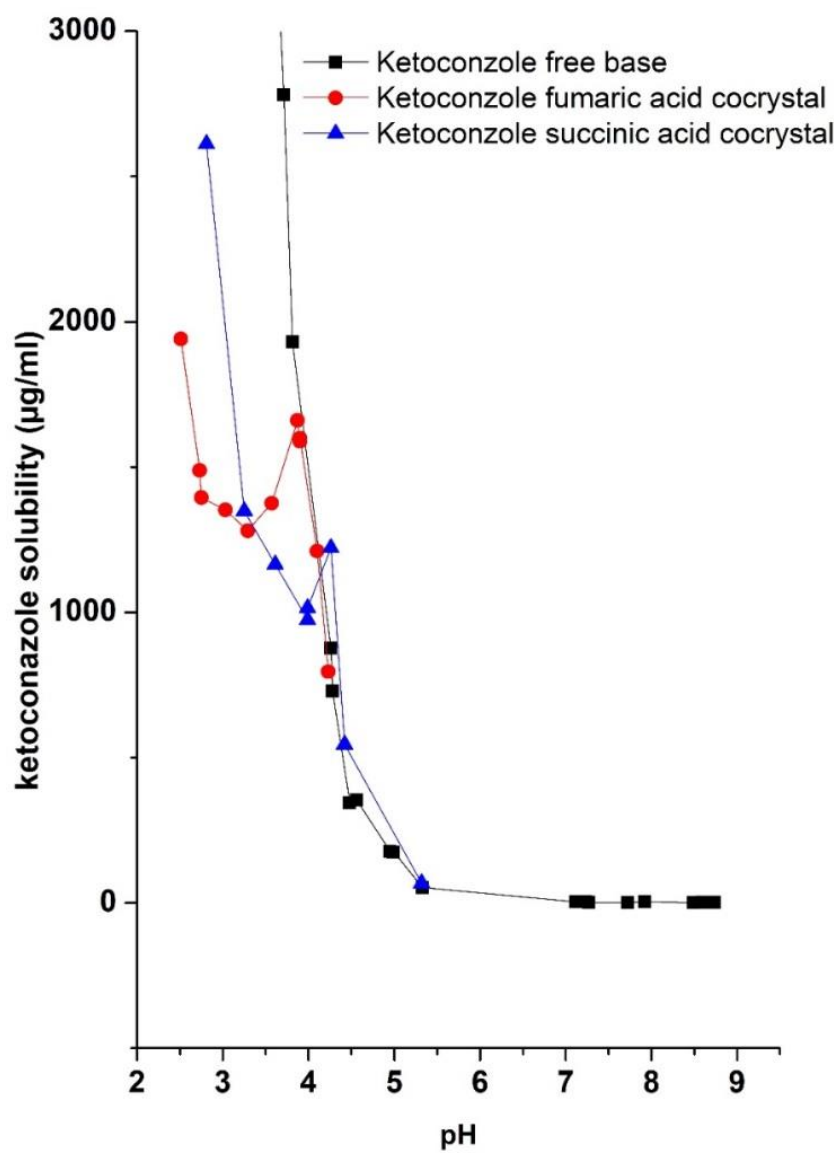

Figure 5. $\mathrm{pH}$ versus solubility profiles of ketoconazole-fumaric acid and ketoconazole-succinic acid cocrystals determined by using respective acidic coformers at $\mathrm{pH}$ lower than the $\mathrm{pH}$ of saturated solutions of cocrystals in water and by using $\mathrm{NaOH}$ to obtain higher $\mathrm{pH}$. The solubility of the ketoconazole free base determined by adjusting $\mathrm{pH}$ with $\mathrm{HCl}$ is also plotted for reference. 
Table 2. Solubility of ketoconazole (KTZ) base, ketoconazole-fumaric acid cocrystal and ketoconazole-succinic acid cocrystal in different buffer solutions along with initial $\mathrm{pH}$ of buffers and $\mathrm{pH}$ after equilibration with solids. Solubility represent average of three determinations ( \pm standard deviation).

\begin{tabular}{|l|c|c|c|c|c|c|}
\hline \multirow{2}{*}{$\begin{array}{c}\text { Initial } \mathrm{pH} \text { and } \\
\text { buffers used }\end{array}$} & $\begin{array}{c}|c| \\
\text { KH after } \\
\text { equilibrat } \\
\text { ion }\end{array}$ & $\begin{array}{c}\text { Solubility } \\
(\mathrm{mg} / \mathrm{mL})\end{array}$ & $\begin{array}{c}\mathrm{pH} \text { after } \\
\text { equilibration }\end{array}$ & $\begin{array}{c}\text { Solubility } \\
(\mathrm{mg} / \mathrm{mL})\end{array}$ & $\begin{array}{c}\mathrm{pH} \text { after } \\
\text { equilibration }\end{array}$ & $\begin{array}{l}\text { Solubility } \\
(\mathrm{mg} / \mathrm{mL})\end{array}$ \\
\hline $\mathrm{pH} 1.1(0.1 \mathrm{M} \mathrm{HCl})$ & $2.9^{*}$ & $27^{*}$ & $2.03 \pm 0.01$ & $21.54 \pm 0.55$ & $2.52 \pm 0.05$ & $23.99 \pm 0.30$ \\
\hline $\begin{array}{l}\mathrm{pH} 2.1 \mathrm{HCl} / \mathrm{KCl} \\
\text { buffer }\end{array}$ & $3.6^{*}$ & $3.4^{*}$ & $2.89 \pm 0.02$ & $3.39 \pm 0.02$ & $3.38 \pm 0.00$ & $3.69 \pm 0.07$ \\
\hline $\begin{array}{l}\mathrm{pH} 5.0 \text { acetate } \\
\text { buffer }\end{array}$ & 4.95 & 0.13 & $4.31 \pm 0.02$ & $0.60 \pm 0.02$ & $4.60 \pm 0.02$ & $0.38 \pm 0.03$ \\
\hline $\begin{array}{l}\mathrm{pH} \mathrm{7.9} \text { phosphate } \\
\text { buffer }\end{array}$ & $7.82 \pm 0.01$ & $0.001 \pm 0.000$ & $7.17 \pm 0.01$ & $0.003 \pm 0.002$ & $7.14 \pm 0.01$ & $0.006 \pm 0.001$ \\
\hline
\end{tabular}

*Approximate $\mathrm{pH}$ and solubility. As more solid materials are added, $\mathrm{pH}$ shifts and solubility changes.

\section{$p H$ versus solubility profiles of ketoconazole determined by adding fumaric acid and succinic acid}

It has been shown earlier in Fig. 5 that the solubility of cocrystals was influenced by $\mathrm{pH}$; when $\mathrm{pH}$ was raised above $\sim \mathrm{pH} 4.1$, the cocrystals converted gradually to free base and the solubility decreased. On the other hand, when $\mathrm{pH}$ of the solutions was reduced by adding respective acids (coformers), the solid phase in equilibria with solutions remained unchanged and the solubility remained high. It was, therefore, of interest to determine whether a similar $\mathrm{pH}$ versus solubility relationship would exist when ketoconazole free base was used as the starting material and the $\mathrm{pH}$ was adjusted using fumaric acid and succinic acid. In particular, any possible conversion of ketoconazole to cocrystals by the reduction of $\mathrm{pH}$ during the determination of $\mathrm{pH}$-solubility profile was studied.

Figs. 6 and 7 give $\mathrm{pH}$-solubility profiles of ketoconazole with respect to fumaric acid and succinic acid. In these studies, the solutions were equilibrated for 96 h. Both Figs. 6 and 7 were generated by dissolving different amounts of 1:1 molar mixtures of ketoconazole with, respectively, fumaric acid and succinic acid; the $\mathrm{pH}$ shift occurred due to the difference in amounts of acids present in added solids. Separately, solubility studies were also conducted using pre-dissolved solutions of fumaric acid and succinic acid and adding excess ketoconazole base. The results were the same whether physical mixtures were used or the free base was added to acid solutions, which indicate that acids from physical mixtures first dissolved in water and then the free base equilibrated with the solution. Therefore, we have plotted only data from physical mixtures in Figs. 6 and 7. In both of these figures, the solubility of ketoconazole increased gradually with the decrease in $\mathrm{pH}$, and, after reaching peak solubilities in the $\mathrm{pH}$ range of 3.5 to 4.0 , the solubility decreased with further addition of ketoconazole-coformer mixture or the coformer alone. Thus, it is apparent that, similar to $\mathrm{pH}_{\max }$ (the $\mathrm{pH}$ of maximum solubility) generally observed in the $\mathrm{pH}$-solubility profile of a free base and its salt form, the $\mathrm{pH}_{\max }$ also exists for the cocrystal formation in aqueous media. It was confirmed by DSC analysis and in situ Raman analysis that, above such $\mathrm{pH}_{\max }$, solutions in both Figs. 6 and 7 were in equilibria with the solid free base. Below $\mathrm{pH}_{\max }$, solid phases in equilibria with solutions were mixtures of cocrystals and free base. This is because when the maximum solubility was reached at $\mathrm{pH}_{\max }$ due the lowering of $\mathrm{pH}$, the equilibrium solid phase was the free base, and, although the cocrystals crystallized out of solutions upon further lowering of $\mathrm{pH}$, the undissolved free base did not readily convert to cocrystals and formed physical mixtures with cocrystals. However, upon further addition of fumaric acid or succinic acid to decrease $\mathrm{pH}$, the free base in the solid phase gradually decreased and the solid converted fully to cocrystals. The $\mathrm{pH}$ versus solubility profile of ketoconazole as determined by lowering the $\mathrm{pH}$ of free base with $\mathrm{HCl}$, as shown earlier in Fig. 4, is also partially superimposed in Figs. 6 and 7 for 
comparison. It is evident that until the onset of cocrystal formation (i.e, above the $\mathrm{pH}_{\max }$ ), $\mathrm{pH}$-solubility profiles were similar whether they were determined by adjusting $\mathrm{pH}$ with fumaric acid, succinic acid or $\mathrm{HCl}$. The solubility is also similar to that shown in Fig. 5 by increasing $\mathrm{pH}$ of cocrystal solutions with $\mathrm{NaOH}$. Thus, the solubility above $\mathrm{pH}_{\max }$ was the same for free base and cocrystal and there was no special influence of cocrystal formation.

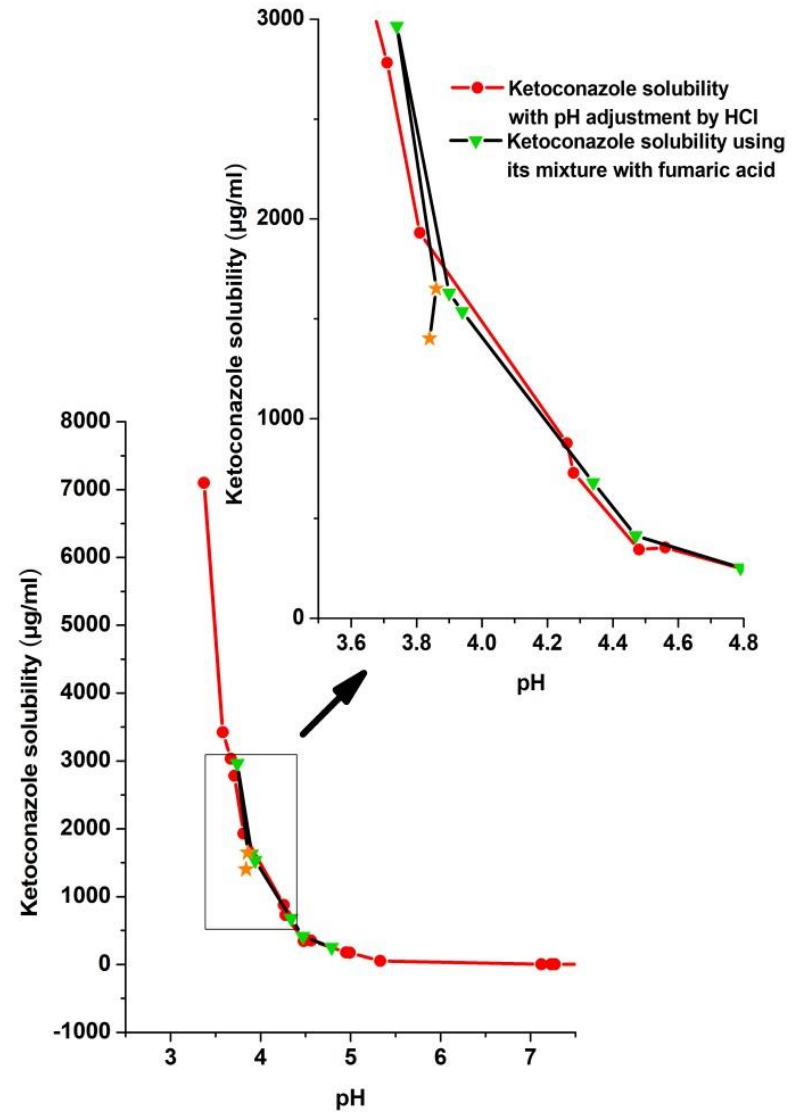

Figure 6. The $\mathrm{pH}$-solubility profile of ketoconazole determined by using different amounts of 1:1 molar physical mixtures of ketoconazole and fumaric acid and equilibrating for $96 \mathrm{~h}$. The $\mathrm{pH}$-solubility profile of ketoconazole determined by $\mathrm{pH}$ adjustment with $\mathrm{HCl}$ is also superimposed for comparison. The solubility profiles from a narrow $\mathrm{pH}$ range (boxed region) is shown in expanded scale in the inset to indicate decrease in ketoconazole solubility after conversion to cocrystal during dissolution of the physical mixture. Asterisk symbols in the figure indicates solubility where both ketoconazole and its cocrystal with fumaric acid coexist in the solid phase.

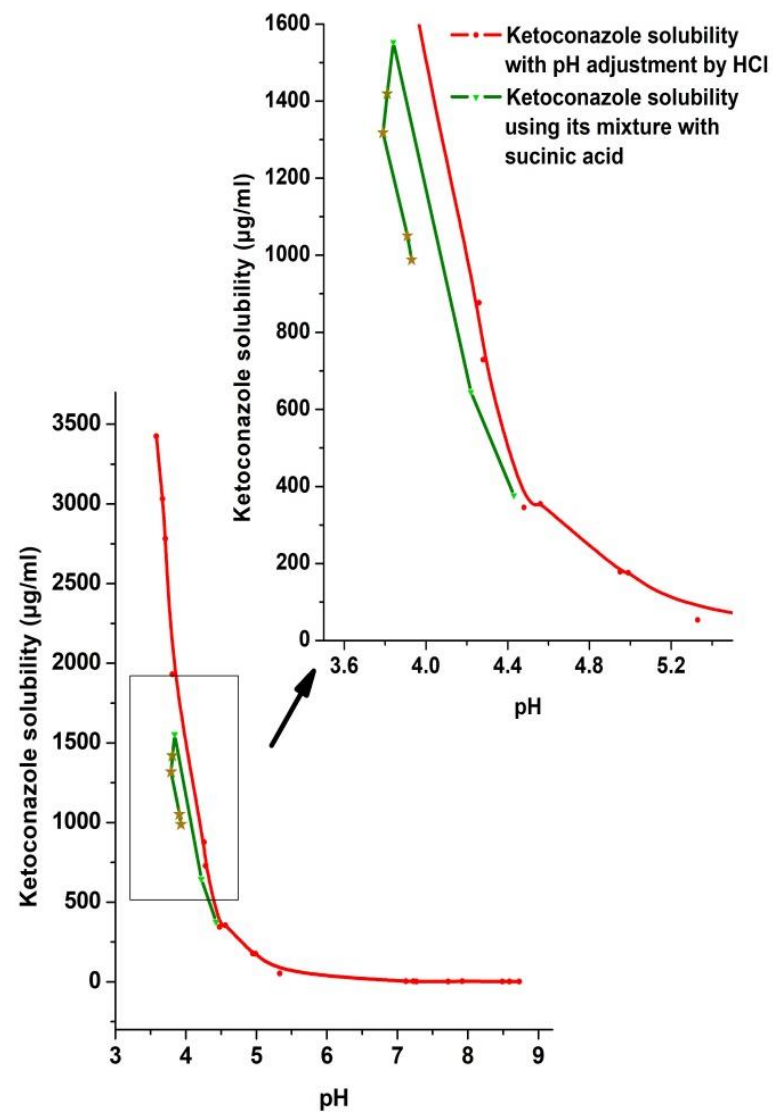

Figure 7. The $\mathrm{pH}$-solubility profile of ketoconazole determined by using different amounts of 1:1 molar physical mixtures of ketoconazole and succinic acid and equilibrating for $96 \mathrm{~h}$. The $\mathrm{pH}$-solubility profile of ketoconazole determined by $\mathrm{pH}$ adjustment with $\mathrm{HCl}$ is also superimposed for comparison. The solubility profiles from a narrow $\mathrm{pH}$ range (boxed region) is shown in expanded scale in the inset to indicate decrease in ketoconazole solubility after conversion to cocrystal during dissolution of the physical mixture. Asterisk symbols in the figure indicates solubility where both ketoconazole and ketoconazole-succinic acid cocrystals coexist in the solid phase.

\section{Effect of equilibration time on ketoconazole solubility and its conversion to cocrystals}

The conversion of ketoconazole to a cocrystal in the solid phase during the determination of $\mathrm{pH}$ solubility profile was a slow process. As mentioned in the Experimental section, the solubility was determined by equilibrating solutions for 4, 24 and $96 \mathrm{~h}$ by shaking aqueous media with excess solids, and when suspensions with excess 1:1 molar mixture of ketoconazole and acids (coformers) at or below $\mathrm{pH}_{\max }$ were equilibrated for $4 \mathrm{~h}$, the solid phase was the free base and no conversion to cocrystal was observed. At $24 \mathrm{~h}$, the solid phase in some of the suspensions was the mixture of free base and cocrystal, and the saturation solubility was not consistently the same when the experiments were repeated, indicating that 
the systems did not reach equilibria. The conversion of free base to cocrystal was also influenced by how much excess solid was present in the system; the conversion to cocrystal was faster as larger amounts of excess solids were added during the determination of solubility. For these reasons, the equilibration period was increased to $96 \mathrm{~h}$, when consistent results with respect to both solubility and conversion to cocrystals were obtained. It may be mentioned here that, in separate experiments, we observed that 1:1 physical mixtures of ketoconazole with coformers can be converted immediately and completely to cocrystals by cogrinding with the addition of a small amount of water. Thus, the conversion of the solid mixtures to cocrystals appears to be dependent on the proximity of ketoconazole and the coformer and how intimately they are mixed.

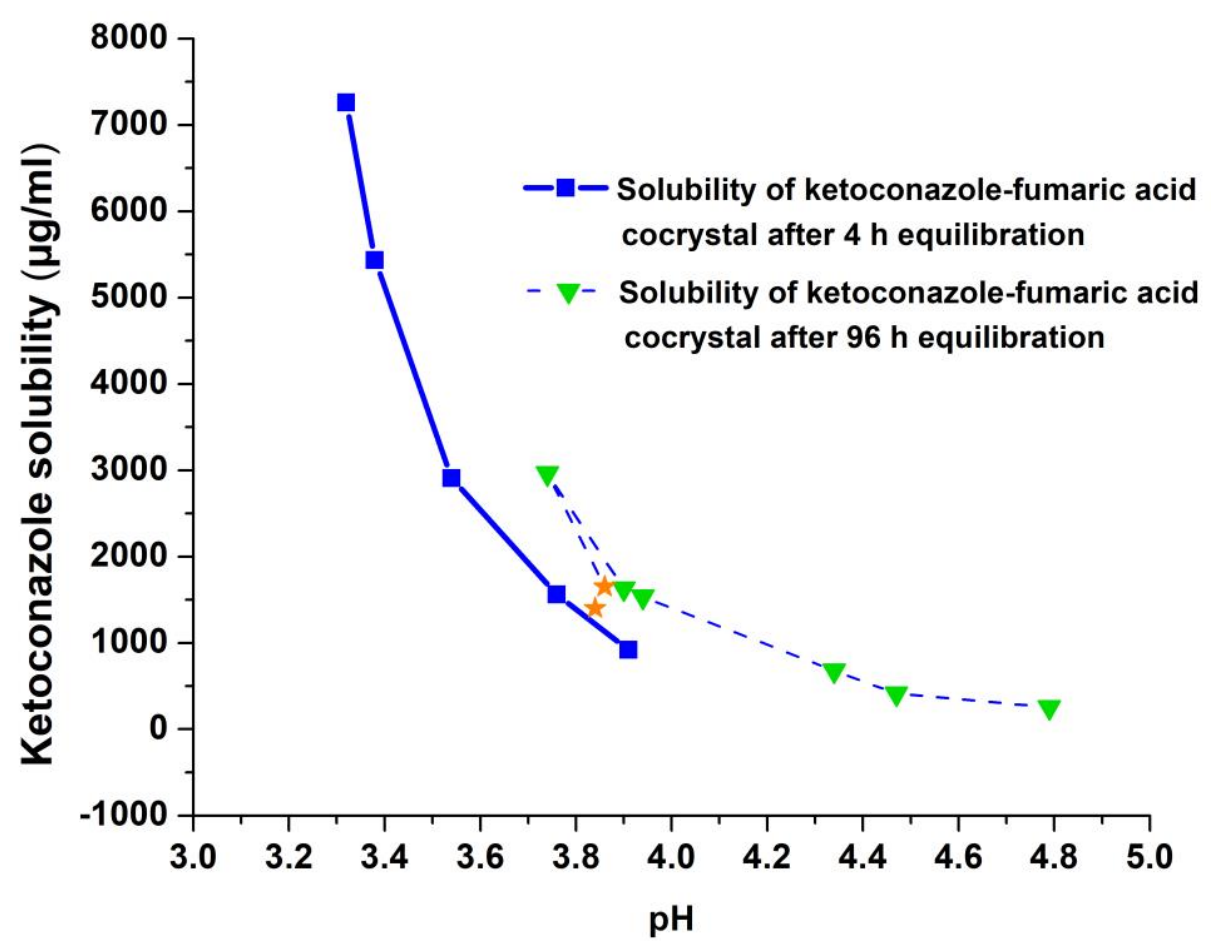

Figure 8. $\mathrm{pH}$-solubility profiles of ketoconazole-fumaric acid physical mixtures after equilibration for 4 and 96 h. Asterisk symbols in the figure indicates solubility where both ketoconazole and ketoconazole-fumaric acid cocrystal coexist in the solid phase.

To demonstrate the effect of equilibration time on the solubility of ketoconazole, pH-solubility profiles of ketoconazole after equilibration with fumaric acid for 4 and $96 \mathrm{~h}$ were determined and the results are given in Fig. 8. In this figure, the solubility profile of ketoconazole after equilibration with fumaric acid at each data point for $4 \mathrm{~h}$ is compared with the solubility profile after equilibration for $96 \mathrm{~h}$ that has been shown earlier in Fig. 7. The solubility of ketoconazole increased gradually and the $\mathrm{pH}$ decreased when increasing amounts of 1:1 ketoconazole-fumaric acid mixture were equilibrated for $4 \mathrm{~h}$ at each time point. The experiment was discontinued when the solubility of ketoconazole reached about $7000 \mu \mathrm{g} / \mathrm{mL}(7$ $\mathrm{mg} / \mathrm{mL}$ ). There was no conversion of the solid phase to cocrystals at any of the data points. In contrast, the maximum solubility of ketoconazole base observed after equilibration for $96 \mathrm{~h}$ was about $3000 \mu \mathrm{g} / \mathrm{mL}(3$ $\mathrm{mg} / \mathrm{mL}$ ) at $\mathrm{pH}^{\sim 3.7}$ and after that the solubility decreased due to the crystallization of ketoconazole-fumaric acid cocrystal. It may also be noticed in Fig. 8 that there was a small increase in pH by about 0.2 unit in the solubility profile determined by equilibration for $96 \mathrm{~h}$ as compared to that for $4 \mathrm{~h}$. The mechanism of this effect was not investigated; however, it could be due to complexation of fumaric acid before or after nucleation into cocrystal and thus being unable to act as the free acid form. 
Essentially similar effects of equilibration time were observed when succinic acid was used to adjust $\mathrm{pH}$ (data not shown). These results demonstrate that equilibrium solubilities of free base and their cocrystals as well as the equilibrium solid phases may differ depending on how long the systems are equilibrated. Therefore, care must be taken in interpreting any solubility differences between free bases and their cocrystal forms by taking the equilibration time into consideration.

\section{Intrinsic dissolution of ketoconazole free base and cocrystals at different $\mathrm{pH}$}

Fig. 9 gives the dissolution profiles of ketoconazole and its cocrystals with fumaric acid and succinic acid at $\mathrm{pH} 3,4$ and 5 from a constant surface area of $0.5 \mathrm{~cm}^{2}$. These $\mathrm{pH}$ conditions were selected because $\mathrm{pH} 3$ was below the $\mathrm{pH}_{\max }, \mathrm{pH} 4$ was at around the $\mathrm{pH}_{\max }$ and $\mathrm{pH} 5$ was above the $\mathrm{pH}_{\max }$.

Additionally, pH-solubility profiles in Figs. 5, 6 and 7 showed a very large decrease in solubility of ketoconazole at $\mathrm{pH} 5$ as compared to those at $\mathrm{pH} 3$ and 4, and it was, therefore, of interest to study whether the difference is also reflected in the dissolution rate. There are two sets of dissolution profiles in Fig. 9: the first was in unbuffered media (left hand column), where the $\mathrm{pH}$ of dissolution media was kept constant by adding $\mathrm{NaOH}$ or $\mathrm{HCl}$, as necessary, and the second was in buffered media (right hand column), where no $\mathrm{pH}$ adjustment was necessary since the $\mathrm{pH}$ did not change due to the dissolution of drug.

The dissolution profiles at $\mathrm{pH} \mathrm{3,4}$ and 5 under $\mathrm{pH}$-stat conditions in unbuffered media in Fig. 9 demonstrate that there was a great impact of cocrystal formation on the dissolution rate of ketoconazole. At all three $\mathrm{pH}$ conditions, dissolutions rates of cocrystals were much higher than those of the free base. Previously, comparative dissolution studies of free base and salt forms of drugs were extensively reported in the literature [30-33], where the higher dissolution rates of salts than that of their respective free base forms were attributed to the difference in microenvironmental $\mathrm{pH}$ conditions. Essentially, the microenvironmental $\mathrm{pH}$ represents the $\mathrm{pH}$ at the surface of solid when the diffusion layer thickness, $h$, approaches zero, i.e., $h=0$, and the solubility of drug at such a $\mathrm{pH}$, and not at the bulk $\mathrm{pH}$ of the dissolution medium, dictates the dissolution rate of drug. The microenvironmental $\mathrm{pH}$ at the surface of dissolving solid

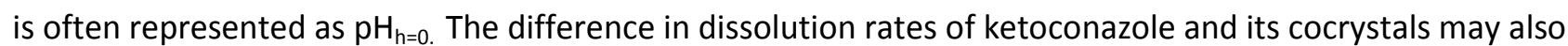
be explained by possible differences in their $\mathrm{pH}_{\mathrm{h}=0 \text {. }}$

To confirm the relationship between microenvironmental $\mathrm{pH}$ and superior dissolution rates of cocrystals as compared to the free base, dissolution studies of cocrystals and the free base at $\mathrm{pH} 3,4$ and 5 were also conducted in buffered media, and the results are given in Fig. 9 in the right hand side along with those in the left hand side for unbuffered media. Table 3 gives their $\mathrm{pH}_{\mathrm{h}=0}$ values under buffered bulk $\mathrm{pH}$ conditions of 3,4 and 5 as determined by the slurry $\mathrm{pH}$ method described earlier in the literature $[30,40]$. Essentially, in the present investigation, about $0.5 \mathrm{~mL}$ of buffer was added to $200 \mathrm{mg}$ of powder in a small vial and mixed by vortexing, and then $\mathrm{pH}$ was recorded when an equilibrium was reached after 5-10 min of mixing. Although no dissolution testing was done at $\mathrm{pH} 7, \mathrm{pH}_{\mathrm{h}=0}$ values at this bulk $\mathrm{pH}$ condition are also given in Table 2 for a comparison with those at $\mathrm{pH}$ 5. It may be observed that $\mathrm{pH}_{\mathrm{h}=0}$ values of ketoconazole cocrystals during dissolution in $\mathrm{pH} \mathrm{3,4}$ and 5 buffers were in the range of 3.13 and 4.38. The dissolution profiles in Fig. 9 are in general agreement with the ketoconazole solubility in this microenvironmental pH range, as shown in Fig. 5. For example, it may be noted in Table 3 that $\mathrm{pH}_{\mathrm{h}=0}$ values of the free base and the two cocrystals in the pH 4 buffer ranged from 4.08 to 4.38 , and due to the similarity in solubility in this $\mathrm{pH}$ range, their dissolution profiles in Fig. 9 were also similar. When the free base by itself is considered, its $\mathrm{pH}_{\mathrm{h}=0}$ values at $\mathrm{pH} 3$ and 4 buffers were, respectively, 4.17 and 4.38 (Table 3 ) and, therefore, its dissolution rates under $\mathrm{pH} 3$ and 4 bulk $\mathrm{pH}$ conditions were also relatively high as compared to that in the $\mathrm{pH} 5$ buffer (Fig. 9), where the microenvironmental pH did not change significantly and the solubility would be low. 
It may be noticed in Table 3 that throughout the wide bulk $\mathrm{pH}$ range of 3 to $7, \mathrm{pH}_{\mathrm{h}=0}$ of the succinic acid cocrystal remained within a narrow range of 4.2 to 4.7 . It is apparent that this is due to the buffering action of succinic acid present in the cocrystal, since succinic acid has two $\mathrm{pK}_{\mathrm{a}}$ values of 4.2 and 5.6 and a buffer would be formed around the lower $\mathrm{pK}_{\mathrm{a}}$ value. The fumaric acid cocrystals exhibited somewhat lower $\mathrm{pH}_{\mathrm{h}=0}$ value since it would possibly buffer to a lower $\mathrm{pH}$ due to lower $\mathrm{pK}_{\mathrm{a}}$ values (3.0 and 4.4). Thus, the acidity of coformers can have certain effects on the dissolution of formed cocrystals as different coformers can modulate microenvironmental $\mathrm{pH}$ differently.
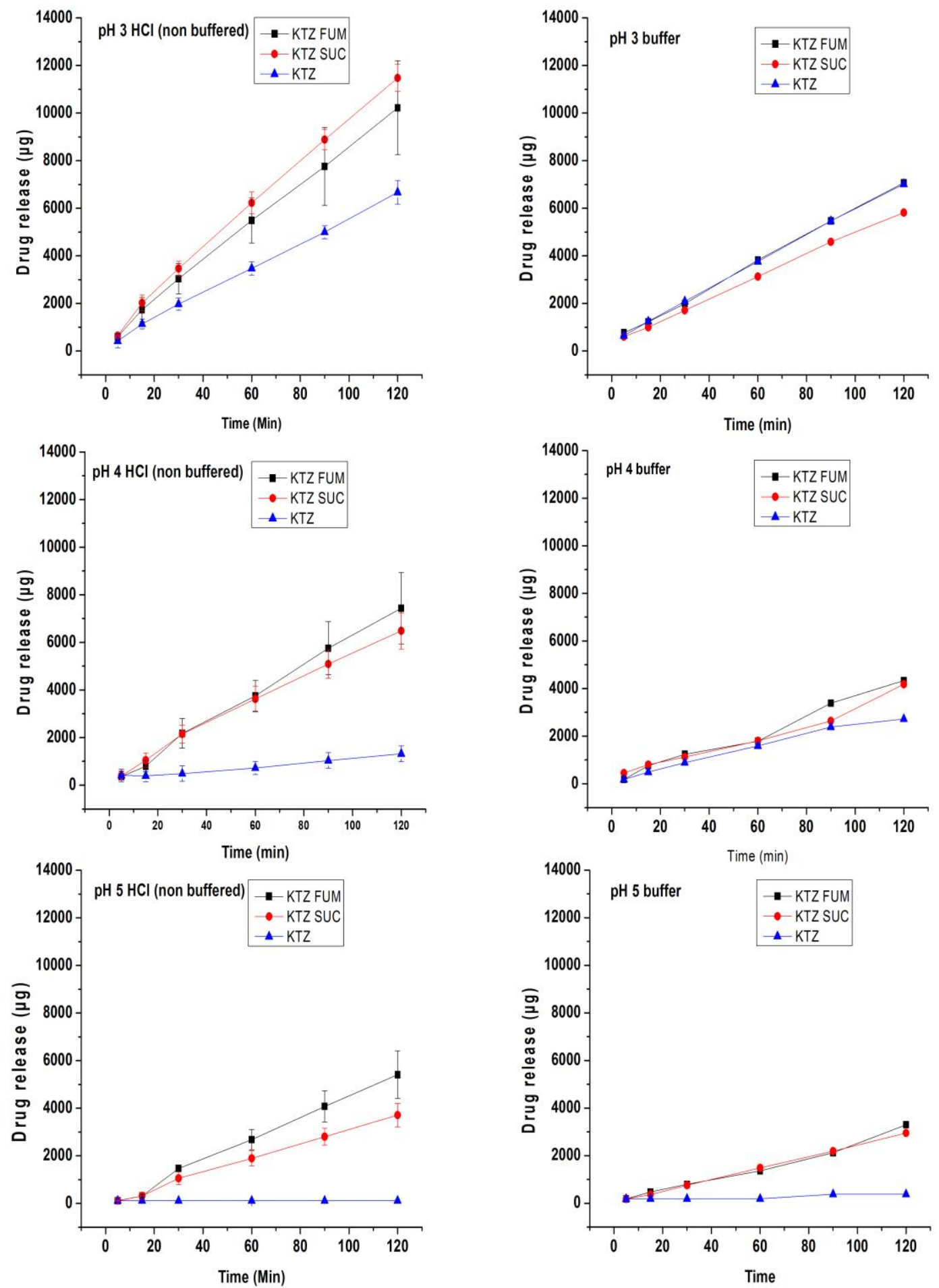

Figure 9. Intrinsic dissolution profiles of ketoconazole base (KTZ) and its cocrystals ketoconazole-fumaric acid (KTZ FUM) and ketoconazole-succinic acid (KTZ SUC) from a constant surface area of $0.5 \mathrm{~cm}^{2}$ in unbuffered media where $\mathrm{pH}$ was kept constant by adding $\mathrm{HCl}$ or $\mathrm{NaOH}$, as necessary (left hand column) and in buffers

(right hand column). 
In addition to the modulation of microenvironmental $\mathrm{pH}$, the dissolution rates of cocrystals and free base may also be influenced by the supersaturation of drugs in the diffusion layer. Such supersaturation was observed earlier during the dissolution of salts [33] and free bases [30], which greatly influenced their dissolution rates. It is possible that a similar supersaturation occurred in diffusion layers during the dissolution of ketoconazole cocrystals at relatively high pH (e.g., $\mathrm{pH} \mathrm{5)}$ due to the acid-base interaction; the dissolution of free base at relatively lower pH (e.g., $\mathrm{pH} 3$ and 4) would also be influenced by such an interaction. Therefore, a combination of the lowering of surface $\mathrm{pH}\left(\mathrm{pH}_{\mathrm{h}=0}\right)$ and the supersaturation of drug in the diffusion layer could be responsible for high dissolution rates of cocrystals observed in $\mathrm{pH} 5$ buffered and unbuffered media. In addition to $\mathrm{pH}_{\mathrm{h}=0}$ values for $\mathrm{pH} \mathrm{3,4}$ and 5 buffers, such values for the $\mathrm{pH} 7$ buffer are also given in Table 3. Since $\mathrm{pH}_{\mathrm{h}=0}$ values for fumaric acid and succinic acid cocrystals at this $\mathrm{pH}$ were, respectively, 4.53 and 4.67 , where the drug solubility is expected to be much higher than that at the $\mathrm{pH}_{\mathrm{h}=0}$ of free base $(\mathrm{pH} 7.05)$, it is expected that dissolution rates of cocrystals at $\mathrm{pH} 7$ would also be much higher than that of the free base.

Table 3. Microenvironmental $\mathrm{pH}\left(\mathrm{pH}_{\mathrm{h}=0}\right)$ at the surface of ketoconazole (KTZ) free base, ketoconazole-fumaric acid (KTZ-FUM) cocrystal and ketoconazole-succinic acid (KTZ-SUC) cocrystal during dissolution testing in different buffers as determined by the slurry $\mathrm{pH}$ method. Each $\mathrm{pH}$ value is the average of two determinations

\begin{tabular}{|l|c|c|c|c|}
\hline \multicolumn{2}{|c|}{ Buffers } & \multicolumn{3}{c|}{$\mathrm{pH}_{\mathrm{h}=0}$ (slurry $\mathrm{pH}$ ) } \\
\hline \multicolumn{1}{|c|}{ Composition } & $\begin{array}{c}\text { Initial } \mathrm{pH} \\
\text { (bulk pH) }\end{array}$ & KTZ base & $\begin{array}{l}\text { KTZ-FUM } \\
\text { cocrystal }\end{array}$ & $\begin{array}{c}\text { KTZ-SUC } \\
\text { cocrystal }\end{array}$ \\
\hline pH 3 phthalate buffer & 2.93 & 4.17 & 3.13 & 4.38 \\
\hline pH 4 phthalate buffer & 3.96 & 4.38 & 4.08 & 4.19 \\
\hline pH 5 neutralized phthalate buffer & 4.97 & 5.00 & 4.23 & 4.40 \\
\hline pH 7 phosphate buffer & 6.97 & 7.05 & 4.53 & 4.67 \\
\hline
\end{tabular}

Surface $\mathrm{pH}$ or $\mathrm{pH}_{\mathrm{h}=0}$ during the dissolution of cocrystals and free base in unbuffered media could not be accurately predicted by the slurry $\mathrm{pH}$ method. Unlike dissolution testing, where $\mathrm{HCl}$ or $\mathrm{NaOH}$ were continuously added to keep the $\mathrm{pH}$ of bulk media constant, no such addition of acid or alkali was possible during the determination of slurry $\mathrm{pH}$. Since the media did not have any buffer capacity, the $\mathrm{pH}$ in presence of excess solids in these media were essentially similar to those in water. However, the dissolution profiles in unbuffered media in Fig. 9 indicated that they were also influenced by the microenvironmental pH at the surface of dissolving solids.

Table 4. Intrinsic dissolution rates of ketoconazole (KTZ) free base and its cocrystals with fumaric acid (KTZ-FUM) and succinic acid (KTZ-SUC) in unbuffered and buffered media at different $\mathrm{pH}$.

\begin{tabular}{|c|c|c|c|c|c|c|}
\hline \multirow{2}{*}{$\mathrm{pH}$} & \multicolumn{6}{|c|}{ Dissolution rate constant $\left(\mu \mathrm{g} \cdot \mathrm{min}^{-1} \cdot \mathrm{cm}^{-2}\right)$} \\
\cline { 2 - 8 } & \multicolumn{3}{|c|}{ Unbuffered media* } & KTZ-FUM & KTZ-SUC & KTZ base \\
\hline $\mathrm{pH} \mathrm{3}$ & 164 & 185 & 106 & 108 & 91 & 108 \\
\hline $\mathrm{pH} \mathrm{4}$ & 124 & 105 & 16 & 71 & 65 & 45 \\
\hline $\mathrm{pH} \mathrm{5}$ & 93 & 62 & $-* *$ & 51 & 48 & $-* *$ \\
\hline
\end{tabular}

* pH of bulk media kept constant by adding $\mathrm{HCl}$ or $\mathrm{NaOH}$ solutions, as necessary

**Extremely low dissolution rate (practically zero) that could not be calculated with accuracy.

Intrinsic dissolution rates of ketoconazole-fumaric acid cocrystal, ketoconazole-succinic acid cocrystal and ketoconazole free base at $\mathrm{pH} \mathrm{3,4}$ and 5, as calculated from the graphs in Fig. 9, are given in Table 4, which essentially confirm high dissolution rates of both cocrystals at pH 3, 4 and 5 mentioned above. In contrast, dissolution rates of the free base decreased with the increase in $\mathrm{pH}$ from 3 to 4 , and at $\mathrm{pH} 5$, the 
dissolution rate decreased to practically negligible level. Although individual values for dissolution rate constants at each $\mathrm{pH}$ may vary due to such factors as microenvironmental $\mathrm{pH}$, supersaturation, etc., mentioned earlier, the results demonstrate that although there may not be significant difference in equilibrium solubility between ketoconazole free base and cocrystals at any particular $\mathrm{pH}$, the cocrystal formation can greatly increase dissolution rates of basic drugs at relatively high $\mathrm{pH}$ conditions by modulating microenvironmental $\mathrm{pH}$ during dissolution testing. Consequently, for certain basic drugs like ketoconazole, dissolution rates of cocrystals could be higher than their respective free base forms. The mechanism why dissolution rates of cocrystals at pH 3, 4 and 5 in Table 4 in unbuffered media were higher than those in buffered media has not been investigated.

\section{Summary and conclusions}

To address different issues with respect to solubility and dissolution rate of cocrystal and their free base form, we have outlined in Introduction of the paper several objectives for the present investigation. Our findings and conclusions against those objectives are summarized below:

a) Comparative solubility of free base and cocrystals as a function of $\mathrm{pH}-\mathrm{pH}$-solubility profiles of ketoconazole cocrystals with fumaric acid and succinic showed $\mathrm{pH}_{\max }(\mathrm{pH}$ of maximum solubility) at $\mathrm{pH}$ $\sim$ 3.5-4.0. Under $\mathrm{pH}$ conditions above $\mathrm{pH}_{\max }$, the solubility profiles were identical whether fumaric acid, succinic acid, $\mathrm{HCl}$ or $\mathrm{NaOH}$ were used to adjust $\mathrm{pH}$, and the profiles were also similar whether the free base or cocrystals were used as starting materials to determine solubility. At $\mathrm{pH}<\mathrm{pHmax}$, the solubility decreased in case of the addition of fumaric acid and succinic acid due to the formation of cocrystals, while the solubility continued to increase when $\mathrm{HCl}$ was added to lower $\mathrm{pH}$ as no cocrystal or salt were formed. Thus, above $\mathrm{pH}_{\max }$ (in this case $\mathrm{pH}^{\sim} 4$ ), there is no solubility advantage of cocrystal formation if the $\mathrm{pH}$ is maintained the same, and the solubility may differ only if $\mathrm{pH}$ of saturated solutions of free base and cocrystals also differ. Usually, $\mathrm{pH}$ values of the suspensions of cocrystals in water are lower than those of the free base in water, and, as a result, cocrystals usually exhibit higher solubility.

b) Solid phases in equilibria with saturated solutions - During the determination of $\mathrm{pH}$-solubility profiles of ketoconazole by adding fumaric acid, succinic acid or $\mathrm{HCl}$, the solubility continued to increase according to the Henderson-Hasselbalch equation and the solid phase in equilibria with solutions was only the free base. After reaching a relatively high solubility at a certain $\mathrm{pH}$ during the addition fumaric acid or succinic acid, which may be referred to as $\mathrm{pH}_{\max }$ or the $\mathrm{pH}$ of maximum solubility, the cocrystal precipitated out. Initially, the precipitate was a mixture of cocrystal and free base as the conversion of free base to cocrystal in the excess solid present was relatively slow. When the $\mathrm{pH}$-solubility profile was determined by adding $\mathrm{HCl}$, instead of the addition of fumaric acid or succinic acid, free ketoconazole base was always the equilibrium species as no cocrystals or salts were formed. When cocrystals were used as starting materials, instead of the free base, for the determination of $\mathrm{pH}$ solubility profile, the excess solids at $\mathrm{pH}_{\max }$ and lower were only cocrystals, and mixtures of cocrystals and free base were present when the $\mathrm{pH}$ was raised above $\mathrm{pH}_{\max }$. Thus, the conversion from free base to cocrystal and vice versa occur, respectively, when the $\mathrm{pH}$ is decreased below or increased above the $\mathrm{pH}_{\max .}$

c) Similarity in $\mathrm{pH}$ vs solubility profiles of cocrystals and salt - $\mathrm{pH}$-solubility profiles of ketoconazolefumaric acid and ketoconazole-succinic acid cocrystals obtained in the present investigation appeared to be similar to $\mathrm{pH}$-solubility profiles commonly encountered with salts. In both cases, there are $\mathrm{pH}_{\max }$ (the $\mathrm{pH}$ of maximum solubility) and the free base is the equilibrium species at $\mathrm{pH}>\mathrm{pH}_{\max }$. The only difference between the solubility profiles of cocrystals and salts is the nature of solid phases at 
$\mathrm{pH}<\mathrm{pH}_{\max }$; it is cocrystal in the $\mathrm{pH}$-solubility profile of cocrystal, while salt is the equilibrium species in the $\mathrm{pH}$-solubility profile of salt. Considering the phenomenon in another way, the two solid phases at $\mathrm{pH}<\mathrm{pH}_{\text {max }}$ have certain similarities as both are complexes, the cocrystal being an acid-base nonionic complex and salt being an acid-base ionic complex. Accordingly, since both cocrystal and salt are solid complexes with definite stoichiometric ratios between basic drugs with acidic conformer or counter ion, the cocrystal may be considered as a new chemical entity similar to a salt.

d) Cocrystal vs free base intrinsic dissolution rates - Although the solubility of cocrystals and the free base were identical at $\mathrm{pH}>\mathrm{pH}_{\max }$, their dissolution rates differed. Dissolution rates of cocrystals were found to be much higher than that of the free base at such $\mathrm{pH}$ due to the modulation of microenvironmental $\mathrm{pH}$ at the dissolving surface of cocrystals. For example, at $\mathrm{pH} 5$, the dissolution rate of the cocrystal was higher than that of the free base, because the $\mathrm{pH}$ at the surface of cocrystal was lower than 5 , where the solubility of ketoconazole was much higher. It was also predicted by determining microenvironmental $\mathrm{pH}$ that the dissolution rates of cocrystals at $\mathrm{pH} 7$ would also be much higher than that of the free base. Thus, under intestinal pH conditions, the cocrystals can have better dissolution rates and, possibly, better bioavailability.

It is hoped that the results presented in this report will clarify some of the basic concepts with respect to solubility and dissolution rates of cocrystals and will provide a systematic approach to identify and select cocrystals for dosage form development. It should, however, be mentioned here that the results may be particularly applicable to basic drugs that demonstrate $\mathrm{pH}$-dependent profiles in the gastrointestinal $\mathrm{pH}$ range. The concepts may also be applicable to cocrystals of acidic compound. However, they may not be generalized for cocrystals of neutral compounds where no significant change in solubility as a function of $\mathrm{pH}$ is observed. Further studies with cocrystals of relatively neutral compounds are currently underway in our laboratory.

\section{Acknowledgement:}

This work was presented, in part, at the special session on 'Pharmaceutical Cocrystals - Physicochemical Properties and Formulations' held at the $6^{\text {th }}$ World Conference on Physico-Chemical Methods in Drug Discovery and Development that was organized by International Association of Physical Chemists (IAPC-6), at Zagreb, Croatia, in September 2017. Further studies were conducted based on feedback received from the participants of the session. The author Abu Serajuddin thanks Dr. Alex Avdeef (in-ADME Research, New York) and Prof. Zoran Mandić (University of Zagreb, Croatia) for invitation to the conference, and he is also grateful to Prof. Mandić for continued encouragement to write this paper.

Conflict of interest: Authors declare no conflict of interest associated with the present research work.

\section{References}

[1] J. Aaltonen, M. Alleso, S. Mirza, V. Koradia, K.C. Gordon, J. Rantanen. Solid form screening--a review. European Journal of Pharmaceutics and Biopharmaceutics 71 (2009) 23-37.

[2] P. Vishweshwar, J.A. McMahon, J.A. Bis, M.J. Zaworotko. Pharmaceutical co-crystals. Journal of Pharmaceutical Sciences 95 (2006) 499-516.

[3] N. Schultheiss, A. Newman. Pharmaceutical cocrystals and their physicochemical properties. Crystal Growth \& Design 9 (2009) 2950-2967. 
[4] P. Cerreia Vioglio, M.R. Chierotti, R. Gobetto. Pharmaceutical aspects of salt and cocrystal forms of APIs and characterization challenges. Advanced Drug Delivery Reviews 117 (2017) 86-110.

[5] D. Douroumis, S.A. Ross, A. Nokhodchi. Advanced methodologies for cocrystal synthesis. Advanced Drug Delivery Reviews 117 (2017) 178-195.

[6] FDA: Regulatory Classification of Pharmaceutical Co-Crystals Guidance for Industry. https://www.fda.gov/downloads/Drugs/Guidances/UCM281764.pdf. Published in February 2018. Last accessed August 17, 2018.

[7] S. Aitipamula, R. Banerjee, A.K. Bansal, K. Biradha, M.L. Cheney, A.R. Choudhury, G.R. Desiraju, A.G. Dikundwar, R. Dubey, N. Duggirala, P.P. Ghogale, S. Ghosh, P.K. Goswami, N.R. Goud, R.R.K.R. Jetti, P. Karpinski, P. Kaushik, D. Kumar, V. Kumar, B. Moulton, A. Mukherjee, G. Mukherjee, A.S. Myerson, V. Puri, A. Ramanan, T. Rajamannar, C.M. Reddy, N. Rodriguez-Hornedo, R.D. Rogers, T.N.G. Row, P. Sanphui, N. Shan, G. Shete, A. Singh, C.C. Sun, J.A. Swift, R. Thaimattam, T.S. Thakur, R. Kumar Thaper, S.P. Thomas, S. Tothadi, V.R. Vangala, N. Variankaval, P. Vishweshwar, D.R. Weyna, M.J. Zaworotko. Polymorphs, salts, and cocrystals: What's in a name? Crystal Growth \& Design 12 (2012) 2147-2152.

[8] D.J. Berry, J.W. Steed. Pharmaceutical cocrystals, salts and multicomponent systems; intermolecular interactions and property based design. Advanced Drug Delivery Reviews 117 (2017) 3-24.

[9] D.P. Kale, S.S. Zode, A.K. Bansal. Challenges in translational development of pharmaceutical cocrystals. Journal of Pharmaceutical Sciences 106 (2017) 457-470.

[10] R.M. Poole, R.T. Dungo. Ipragliflozin: first global approval. Drugs 74 (2014) 611-617.

[11] A. Kumar, S. Kumar, A. Nanda. A Review about regulatory status and recent patents of pharmaceutical co-crystals. Advanced Pharmaceutical Bulletin 8 (2018) 355-363.

[12] L. Feng, P.H. Karpinski, P. Sutton, Y. Liu, D.F. Hook, B. Hu, T.J. Blacklock, P. E. Fanwick, M. Prashad, S. Godtfredsen, C. Ziltener. LCZ696: a dual-acting sodium supramolecular complex. Tetrahedron letters 53 (2012) 275-276.

[13] Assessment report: Steglatro, European Medicines Agency, 25 January, 2018. https://www.ema.europa.eu/documents/assessment-report/steglatro-epar-public-assessmentreport en.pdf. Last accessed January 12, 2019.

[14] R. Thakuria, A. Delori, W. Jones, M.P. Lipert, L. Roy, N. Rodríguez-Hornedo. Pharmaceutical cocrystals and poorly soluble drugs. International Journal of Pharmaceutics 453 (2013) 101-125.

[15] D.J. Good, N. Rodríguez-Hornedo. Solubility advantage of pharmaceutical cocrystals. Crystal Growth \& Design 9 (2009) 2252-2264.

[16] A. Kozak, P.H. Marek, E. Pindelska. Structural characterization and pharmaceutical properties of three novel cocrystals of ethenzamide with aliphatic dicarboxylic acids. Journal of Pharmaceutical Sciences 108 (2019) 1476-1485. (https://doi.org/10.1016/j.xphs.2018.10.060)

[17] M.K. Stanton, A. Bak. Physicochemical properties of pharmaceutical co-crystals: A case study of ten AMG 517 co-crystals. Crystal Growth \& Design 8 (2008) 3856-3862.

[18] R. Chadha, A. Saini, S. Khullar, D.S. Jain, S.K. Mandal, T.N. Guru Row. Crystal structures and physicochemical properties of four new lamotrigine multicomponent forms. Crystal Growth \& Design 13 (2013) 858-870.

[19] Y. Gao, J. Gao, Z. Liu, H. Kan, H. Zu, W. Sun, J. Zhang, S. Qian. Coformer selection based on degradation pathway of drugs: a case study of adefovir dipivoxil-saccharin and adefovir dipivoxilnicotinamide cocrystals. International Journal of Pharmaceutics 438 (2012) 327-335.

[20] M.L. Cheney, N. Shan, E.R. Healey, M. Hanna, L. Wojtas, M.J. Zaworotko, V. Sava, S. Song, J.R. Sanchez-Ramos. Effects of crystal form on solubility and pharmacokinetics: A crystal engineering case study of lamotrigine. Crystal Growth \& Design 10 (2010) 394-405.

[21] C. Ràfols, H. Fael, E. Fuguet, B. Outhwaite, S. Lee, R. Ruiz. Dissolution rates of ciprofloxacin and its cocrystal with resorcinol. ADMET and DMPK 6 (2018) 61-70. 
[22] Y.M. Chen, N. Rodríguez-Hornedo. Cocrystals Mitigate negative effects of high pH on solubility and dissolution of a basic drug. Crystal Growth \& Design 18 (2018) 1358-1366.

[23] M.R. Shimpi, A. Alhayali, K.L. Cavanagh, N. Rodríguez-Hornedo, S.P. Velaga. Tadalafil-malonic acid cocrystal: Physicochemical characterization, pH-solubility, and supersaturation studies. Crystal Growth \& Design 18 (2018) 4378-4387.

[24] N.J. Babu, A. Nangia. Solubility advantage of amorphous drugs and pharmaceutical cocrystals. Crystal Growth \& Design 11 (2011) 2662-2679.

[25] K.L. Cavanagh, C. Maheshwari, N. Rodríguez-Hornedo. Understanding the differences between cocrystal and salt aqueous solubilities. Journal of Pharmaceutical Sciences 107 (2018) 113-120.

[26] A. Avdeef. Cocrystal solubility product prediction using an in combo model and simulations to improve design of experiments. Pharmaceutical Research 35 (2018) 40.

[27] M.T. Esclusa-Diaz, M. Guimaraens-Méndez, M.B. Pérez-Marcos, J.L. Vila-Jato, J.J. Torres-Labandeira. Characterization and in vitro dissolution behaviour of ketoconazole/ $\beta$ - and 2-hydroxypropyl- $\beta$ cyclodextrin inclusion compounds. International Journal of Pharmaceutics 143 (1996) 203-210.

[28] F.A. Martin, M.M. Pop, G. Borodi, X. Filip, I. Kacso. Ketoconazole salt and co-crystals with enhanced aqueous solubility. Crystal Growth \& Design 13 (2013) 4295-4304.

[29] A.T.M. Serajuddin, C.I. Jarowski. Effect of diffusion layer $\mathrm{pH}$ and solubility on the dissolution rate of pharmaceutical acids and their sodium salts. II: Salicylic acid, theophylline, and benzoic acid. Journal of Pharmaceutical Sciences 74 (1985) 148-154.

[30] A.T.M. Serajuddin, C.I. Jarowski. Effect of diffusion layer $\mathrm{pH}$ and solubility on the dissolution rate of pharmaceutical bases and their hydrochloride salts I: Phenazopyridine. Journal of Pharmaceutical Sciences 74 (1985) 142-147.

[31] A.T.M. Serajuddin. M. Pudipeddi, D. J. W. Grant, P. H. Stahl. Solubility and dissolution of weak acids, bases, and salts. In Handbook of Pharmaceutical Salts: Properties, Selection, and Use. , Wiley-VCH, Zurich, Switzerland, 2002, pp. 19-39.

[32] A.T. Serajuddin. Salt formation to improve drug solubility. Advanced Drug Delivery Reviews 59 (2007) 603-616.

[33] S. Li, S. Wong, S. Sethia, H. Almoazen, Y.M. Joshi, A.T. Serajuddin. Investigation of solubility and dissolution of a free base and two different salt forms as a function of $\mathrm{pH}$. Pharmaceutical Research 22 (2005) 628-635.

[34] A. Avdeef, E. Fuguet, A. Llinàs, C. Ràfols, E. Bosch, G. Völgyi, T. Verbić, E. Boldyreva, K. Takács-Novák. Equilibrium solubility measurement of ionizable drugs - consensus recommendations for improving data quality. ADMET \& DMPK 4 (2016) 117-178. (http://dx.doi.org/10.5599/admet.4.2.292)

[35] O.S. Marković, M.P. Pešić, A.V. Shah, A.T.M. Serajuddin, T.ž. Verbić, A. Avdeef. Solubility-pH profile of desipramine hydrochloride in saline phosphate buffer: Enhanced solubility due to drug-buffer aggregates. European Journal of Pharmaceutical Sciences (2019). (https://doi.org/10.1016/i.eips.2019.03.014)

[36] S.L. Childs, G.P. Stahly, A. Park. The salt-cocrystal continuum: The influence of crystal structure on ionization state. Molecular Pharmaceutics 4 (2007) 323-338.

[37] M.M. Al-Shalalfeh, A.T. Onawole, T.A. Saleh, A.A. Al-Saadi. Spherical silver nanoparticles as substrates in surface-enhanced Raman spectroscopy for enhanced characterization of ketoconazole. Materials Science \& Engineering. C, Materials for Biological Applications 76 (2017) 356-364.

[38] M. Suzuki, T. Shimanouchi. Infrared and Raman spectra of succinic acid crystal. Journal of Molecular Spectroscopy 28 (1968) 394-410.

[39] A.H. Hosmani, Y.S. Thorat. Synthesis and evaluation of nanostructured particles of salt of ketoconazole for solubility enhancement. Digest Journal of Nanomaterials and Biostructures 6 (2011) 1411-1418. 
[40] M. Pudipeddi, E.A. Zannou, M. Vasanthavada, A. Dontabhaktuni, A.E. Royce, Y.M. Joshi, A.T.M. Serajuddin. Measurement of surface $\mathrm{pH}$ of pharmaceutical solids: A critical evaluation of indicator dye-sorption method and its comparison with slurry $\mathrm{pH}$ method. Journal of Pharmaceutical Sciences 97 (2008) 1831-1842.

(C)2019 by the authors; licensee IAPC, Zagreb, Croatia. This article is an open-access article distributed under the terms and conditions of the Creative Commons Attribution license (http://creativecommons.org/licenses/by/3.0/) (cc)) BY 